\title{
NATIONAL IDENTITY AND NEW ZEALAND'S ACTIONS \\ ON THE UNITED NATIONS SECURITY COUNCIL: \\ 1993-94 AND 2015-16
}

BY

\section{KATE BREACH}

A thesis

submitted to the Victoria University of Wellington in fulfilment of the requirements for the degree of Master of International Relations

Victoria University of Wellington 
Table of Contents

$\begin{array}{lr}\text { Abstract } & 3\end{array}$

$\begin{array}{lr}\text { I. Introduction } & 4\end{array}$

$\begin{array}{lr}\text { II. Theory and Methodology } & 8\end{array}$

Neo-realism 10

Neo-liberalism 11

$\begin{array}{lr}\text { Constructivism } & 13\end{array}$

$\begin{array}{lr}\text { A Pragmatic Combined Analytical Framework } & 17\end{array}$

$\begin{array}{lr}\text { Methodology } & 18\end{array}$

III. Literature Review: New Zealand's National Identity in Historical and International Relations Scholarship

Historical Establishment of New Zealand's National Identity 20

New Zealand National Identity in Contemporary International Relations Scholarship 26

IV. New Zealand's National Identity Content and Internalisation 3

Constitutive Norms: Historical, Cultural and Territorial Identity Content 34

Social Purpose: Moral and Political Identity Content 41

Cognitive Model: World View Identity Content 46

Relational: What New Zealand is Not 49

V. New Zealand's Actions on the United Nations Security Council: 1993-94 and 2015-16 50

The UN Security Council $\quad 50$

New Zealand on the UNSC, 1993-94

New Zealand on the UNSC, 2015-16 58

A Comparison of Two UNSC Tenures $\quad 65$

$\begin{array}{lr}\text { VI. Conclusion } & 67\end{array}$

$\begin{array}{lr}\text { Bibliography } & \mathbf{7 0}\end{array}$ 


\section{Abstract}

To win its seat on the United Nations Security Council (UNSC) in both 1993-94 and 201516, New Zealand campaigned using the same prime pillar; its ability to act independently on the world's prime authority for maintenance of international peace and security. With the substantial change in New Zealand's international relationships between the two UNSC tenures, most particularly with the United States of America and China, many commentators have questioned whether New Zealand still acts independently in international affairs. Employing analytic eclecticism, this thesis applied a combined analytical framework to assess the drive behind New Zealand's actions during both its 1993-94 and 2015-16 UNSC tenures, allowing both traditional international relations theories of neo-realism and neoliberalism and the constructivist lens of national identity to be combined for greater explanatory power for the state's actions in the contemporary era of complex international interdependencies. This research determined that most of New Zealand's actions aligned with pursuit of its interests, as a small state, as ensured through multilateralism under the lens of institutional neo-liberalism. However, a number of actions taken, and strong positions held, by New Zealand on the UNSC in both periods did not align with the state's pursuit of material interests under traditional international relations theories. By first establishing the popularly internalised national identity characteristics (or content) during each UNSC tenure period, defined as residing in public opinion, this thesis argues that a 'win-set' of national identity content relative prioritisation during each period enabled, and arguably drove, New Zealand's political elite to take actions or hold positions not aligned with those of powerful states on which the small country's material interests depended. It is argued that New Zealand's actions on the UNSC in 2015-16 reinforced the social construction of New Zealand's internationally regarded national identity content as an independent advocate for the global good, which was strongly established during its 1993-94 tenure. 


\section{Introduction}

On 17 October 2014, New Zealand successfully won one of the ten non-permanent seats on the United Nations Security Council (UNSC), and subsequently carried out its two-year tenure from 1 January 2015 to 31 December 2016. The win successfully punctuated a decade of promoting the key pillars of the country's campaign to the international community; that New Zealand would act on the UNSC with integrity, independence and innovation (New Zealand Government 2013, 1).

New Zealand last sat on the UNSC from 1993-94, 21 years earlier. To win election by the United Nations General Assembly (UNGA) member states for the 1993-94 term, the country successfully campaigned using a key pillar common to that of its 2015-16 campaign; the claim of independence, as guaranteed by New Zealand's independent foreign policy (O'Brien 2013, 14). It is noted by many scholars that New Zealand's external dependencies have changed markedly over the late 20th and early 21 st century, as it has moved out from under the legacy of colonialism and World War Two (WWII) alliances, and taken its place as a member state in the Asia-Pacific region. As such, New Zealand in 2015 had very different international relationships and dependencies to those it held in 1993 (O'Brien 2015, 8). This change is most significant in New Zealand's relationships with two of the states that make up the five permanent members (P5) of the UNSC: China and the United States of America (US). In the last decade, China has become New Zealand's second largest export market (Statistics New Zealand 2015a) while the US and New Zealand have signed agreements for a closer strategic relationship (New Zealand Ministry of Foreign Affairs and Trade 2010), and developed potential for increased trade between the two countries under negotiations of the Trans Pacific Partnership (TPP) agreement (Ayson 2013, 353).

This marked change in New Zealand's strategic relationship or economic dependency with two powerful states who, as P5, hold the power to veto any resolution raised by the UNSC (United Nations 1945), raises a key question in relation to the country's 2015-16 UNSC campaign and tenure. Why did the key campaign pillar of New Zealand's independence rally strongly enough with the UNGA to win New Zealand its 2015-16 seat, when New Zealand's economic and strategic dependence had clearly increased on China and the US? 
The purpose of this research has been to conduct a comparative analysis of New Zealand's actions during both its 1993-94 and 2015-16 UNSC tenures, to explain New Zealand's actions as either; aligning with pursuit of its material interests and aligning to characteristics (or content) of its national identity, where the relevant characteristic/content of the New Zealand national identity has been popularly internalised by the New Zealand public, or; aligning only with its national identity. This research is significant in the discussion of New Zealand foreign policy as little scholarship currently exists on national identity influence on New Zealand's actions in the international political arena, and no direct analysis can be found that undertakes to explain New Zealand's actions on the UNSC through a national identity lens. This thesis advances extant IR scholarship on New Zealand foreign policy by conducting analysis using a combined theoretical framework in order to provide greater explanatory power for New Zealand's actions than can be provided through the paradigm of single IR theories alone. This thesis aims to reduce errors of simplification in application of singular IR theories to analysis of complex international engagements conducted by New Zealand during its UNSC tenures by employing analytic eclecticism. Analytic eclecticism in IR scholarship, posited by Katzenstein and Sil in the last decade, aims to reduce the disparity in between explanations for international actions provided by IR academic inquiry and real world international action and policy (Sil and Katzenstein 2010b, 2). As put forward by Katzenstein and Sil, and as applied in this thesis, analytic eclecticism is an approach applied to international relations (IR) research that allows employment of a combined analytic framework of theories, with ontologies stipulating different paradigmatic assumptions, and then highlights practically useful connections between analysis conducted separately under each theory's research traditions. A key characteristic of the approach of analytic eclecticism relevant to this thesis is the "distinctive value added in relating academic debates to concrete matters of policy and practice" (Sil and Katzenstein 2010a, 1). This thesis advances IR scholarship of New Zealand foreign policy by applying the analytical approach of analytic eclecticism to enable greater explanatory power and provide a pragmatic theoretical basis to explain New Zealand's real world international actions in the complex modern era of interdependence and globalisation.

Analysis of New Zealand's actions during both of these two UNSC tenures is of particular pertinence, as New Zealand's internationally recognised national identity has potentially been challenged in the 21 years between the tenures by its changing relationships and dependencies in the international system. A significant amount of historical scholarship 
documents the development of the national identity of New Zealand through significant state milestones and international interactions, however little scholarship in IR analyses the international actions of New Zealand through the lens of changing national identity. A number of scholars do attribute some areas of bi-partisan foreign policy consensus in New Zealand politics to national identity but do not ascertain the development of this influence nor use IR theory to explain its impact on New Zealand's actions in the international system. Under analytic eclecticism, this thesis steps forward IR scholarship on national identity in New Zealand foreign policy by incorporating analysis through the lens of national identity as well as traditional IR theories. This approach enriches explanation for New Zealand's actions on the UNSC, most particularly during the era of its contemporary international strategic and economic relationships in the 2015-16 tenure.

Employing analytic eclecticism, this thesis argues that New Zealand's actions on the UNSC in 1993-94 and 2015-16 can be interpreted as either in line with the state's material interests and in line with the country's national identity, or in line with national identity characteristics/content only and not attributable to pursuit of material interests. This thesis uses the term 'national identity content' for characteristics or elements of national identity, in line with the terminology used in extant identity IR scholarship reviewed for this research. Arguing that national identity resides in public opinion, this thesis will establish content of New Zealand's national identity relevant to its actions on the UNSC, as internalised by the New Zealand public. It will then identify changes to the degree of prioritisation of different national identity content between the tenures in 1993-94 and 2015-16. Through analysis of actions taken by New Zealand on the UNSC during those tenures under a combined theoretical framework, this thesis will then argue that the New Zealand political elite acted within the bounds of the New Zealand national identity for those actions that do not align with pursuit of material interests.

This thesis in no way attempts to exhaustively define the New Zealand national identity. National identity, as a collective identity, is a continuously evolving list of content, and the relative priority of content within the national identity will change under the differing contexts that the identity is invoked. This thesis attempts only to argue inclusion of popularly internalised content of the New Zealand national identity that is relevant to the actions taken by New Zealand on the UNSC. This thesis argues that national identity is founded in public 
opinion and foreign policy is only successfully enacted by political elite, meaning domestic support is retained, if that foreign policy aligns with popularly internalised national identity.

The arguments of this thesis are developed across four further chapters. The following chapter outlines the IR theories that are used in the combined theoretical analysis of New Zealand's actions on the UNSC by this thesis, discussing the limitations of traditional IR theories of neo-realism and neo-liberalism in explaining the full actions of the country, and detailing the concepts of the constructivists' approach that, in combination with traditional theories, provide greater explanatory power. The foundation argument for this analytic eclecticism in IR inquiry is established, with benefits and risks discussed. Chapter II then lays out the methodology, embodying analytic eclecticism, that this thesis applies to analysis of New Zealand's actions on the UNSC in both periods to support the argument that the breadth of actions can only most comprehensively be explained by connecting explanations provided by different IR theories. Chapter III presents an historical scholarship review to outline key milestones in the development of the New Zealand national identity and then presents a literature review of IR scholarship on New Zealand's international actions, noting the limited studies on impact of national identity. Chapter IV establishes the content of the New Zealand national identity relevant to its actions on the UNSC, as internalised by the New Zealand population, in both the 1993-94 and 2015-16 periods. The chapter also identifies the impact on degree of prioritisation of national identity content due to changes in New Zealand's international relationships between the two periods. Chapter V sets out the analysis of the actions of New Zealand on the UNSC during its 1993-94 and 2015-16 tenure and identifies these actions as either in line with traditional IR theory explanation of being driven by the state's material interests and in line with the identified New Zealand national identity content, or only in line with identified New Zealand national identity content. The final chapter concludes the main argument of the thesis, bringing together the key elements of the development of this argument and the supporting analysis of New Zealand's two UNSC tenures. 


\section{Theory and Methodology}

New Zealand's actions in international politics are often analysed through the IR theory lenses of neo-realism and neo-liberalism. However, while holding capable explanatory power in early periods of New Zealand's history as an independent state, neither of these traditional IR theories alone can provide adequate explanation for New Zealand's international actions in the modern global era. Constructivism allows for the actions of the state to be interpreted beyond materialistic interests, as driven in the anarchic system common to neo-realism and neo-liberalism, and allows that a state's interests and identity are social constructions that can be mutually constitutive. For this current era, a combined theoretical lens that allows a constructivist approach in addition to neo-realism and neoliberalism allows for a more comprehensive explanatory theoretical framework. Analytic eclecticism in pragmatic IR academic inquiry employs this combined theoretical approach.

In a 2009 opinion piece, renowned IR scholar Joseph Nye lamented that IR scholars were paying less attention to how their work related to the real world, identifying a 'growing gap between theory and policy' (Nye 2009). Inspired by Nye's perspective, Katzenstein and Sil identified a growing disparity of the explanatory power of singular IR theories for complex real world politics in the era post the September 112001 US terrorist attacks (9/11), which inspired their multiple works on the benefits of analytic eclecticism in IR scholarship (Sil and Katzenstein 2010b, xiii). Katzenstein and Sil identified that traditional research methods using single IR theories required simplification of real world dilemmas in order for analytical research problems to fit the ontological assumptions of the theory. Paradigms in single IR theory research have resulted in growing errors between explanation that can be provided by academic research and the international actions or policy employed for the issue in complex real world international engagements. Katzenstein and Sil argue that 'simplifications based on a single theoretical lens involve trade-offs and can produce enduring blind spots' (Sil and Katzenstein 2010b, 9), such that IR academic discourse risks addressing artificially segmented research clusters only, "with little thought to the implications to real-world dilemmas facing political and social actors' (Sil and Katzenstein 2010b, 9). Analytic eclecticism provides avenue to breach the divide between single paradigm explanatory power and real world political problems. 
Katzenstein and Sil define analytic eclecticism as 'any approach that seeks to extricate, translate, and selectively integrate analytic elements... of theories or narratives that have been developed within separate paradigms but that address related aspects of substantive problems that have both scholarly and practical significance' (Sil and Katzenstein 2010b, 10). The approach allows that research findings carried out under single theory can be pragmatically connected, despite the different assumptions the theories are founded upon, in order to provide richer explanation for complex real world dilemmas.

Employment of analytic eclecticism, while bringing benefits of reducing trade-offs and blind spots created by single theory explanation of actions in the international system, holds the risk of theoretical incoherence, as brought by incommensurability across different theories founded on incompatible assumptions, potentially resulting in 'an artificial homogenization of incompatible perspectives' (Sil and Katzenstein 2010a, 4). This risk is minimised if 'concepts and analytic principles are properly understood in their original conceptual frameworks' (Sil and Katzenstein 2010b, 15) and surmountable when analytic eclecticism is presented as a pragmatic inquiry, where knowledge claims are reconsidered and reconstructed 'on the basis of engagement with the experiences of actors seeking to cope with real-world problems' (Sil and Katzenstein 2010a, 7).

Neo-realism, neo-liberalism and constructivism all provide theoretical lenses that can separately offer explanation of New Zealand's actions on the UNSC, when the assumptions the theories are individually founded upon are applied to the action and context under analysis under their separate paradigms. Under analytic eclecticism, individual theory analyses can be pragmatically connected for the same substantive issue, or action, to provide greater explanatory power for the state's action in the international arena and reduce blind spots, so long as the separate analytic principles are understood and applied. This chapter outlines these separate principles and founding assumptions of the three theories that are employed individually for the separate theories under a combined analytic framework before pragmatic connections are drawn between the singular theory analyses to provide the most comprehensive explanation of New Zealand's actions on the UNSC in both 1993-94 and 2015-16. Analytic eclecticism allows the different paradigms of single theories to 'co-exist as part of a more complex, yet usable analytic framework that helps in making sense of concrete social phenomena' (Sil and Katzenstein 2010b, 13), in this case the actions of New 
Zealand in complex global issues during an era of equally complex international strategic and economic relationships.

\section{Neo-realism}

With a population under 10 million, New Zealand is a small state (Thorhallsson 2012, 138) and as such is predicted to act within a limited set of actions in the anarchic international system common to both the traditional IR theories of neo-realism and neo-liberalism. In the neo-realist and neo-liberal anarchic system, states are unitary, like and rational actors that act entirely in self interest; that is to secure the state's preservation and to increase its material capabilities of economic and military power (Waltz 1979, 106-107). Self-interest of all states results in the 'security dilemma' in an anarchic system; where states act only in the interest of self preservation, and where the methods that states employ to ensure their own security can be interpreted as a threat to the security of another state (Axelrod 1984, 4). The structure of the anarchic system, defined by the distribution of relative material capabilities of states, drives the actions of all states (Waltz 1979, 97-100). The only way to alter the actions of states in a system is to change the structure of the system, through a change in the relative distribution of capabilities of the states constituting the system (Waltz 1979, 100). The only impetus for cooperation between states in the system is in advancement of their own self interests, and cannot be guaranteed due to lack of a power above the state to ensure states adhere to agreed actions (Oye 1985, 1).

For neo-realists, the state's self interest to increase material capabilities is driven by the need to achieve relative gains over the capabilities of other states, as deterrent to threats against its sovereignty. For small states such as New Zealand, neo-realism argues that this drives bandwagoning or balancing behaviours of cooperation (Waltz 1979, 125-127). By bandwagoning with the hegemonic state in the system, the small state is provided the 'umbrella' of protection of the hegemon, seen as an increase in its own capabilities. A small state bandwagons so that its existence will not be threatened by the hegemon, or other states in alliance against the hegemon who fear the threat of the hegemon in retaliation. Alternatively, the small state could cooperate with other states to form an alliance of sufficient capabilities relative to the hegemon to balance power in the system between two poles (Walt 1984, 18-19). 
Through a neo-realist lens, in the US hegemonic system of current international politics, the system drives New Zealand to form alliances that either bandwagon with or balance against the power of the US to ensure its preservation. The neo-realist lens holds adequate explanatory power for New Zealand's foreign policy in the post-World War One (WWI) years and through the majority of the Cold War era. In these periods, New Zealand retained close relationships with its traditional Western allies, including the US (McKinnon 2013, 712), and maintained a security bandwagon through the ANZUS alliance treaty with the US, guarding it against the ideational 'other' of communist USSR. However, the decision to deny access for nuclear-powered ships to its ports in 1985 that effectively ended its alliance with the US (McKinnon 2013, 280), contradicts neo-realist predictions for New Zealand's behaviour as a small state. Neo-realism is therefore insufficient alone to explain the international actions of New Zealand in the period beyond this change in the small state's strategic relationship with the US.

\section{Neo-liberalism}

Neo-liberalism provides equally adequate explanation for New Zealand's behaviour in the post WWI years and the Cold War, including actions following New Zealand's nuclear free declaration. Liberalism, established as an IR theory in the post-WWI years as a reaction to the destruction seen as driven by the realist interpretation of international politics, argued that open trade offered rational states the ability to increase their own economic capabilities, and thus power, in a way that benefitted all states and so overcame the security dilemma of the anarchic international system (Nye 1988, 238-240). Neo-liberalism advanced on the liberal 'way of the merchant' theory, with the argument that the anarchic system, with absence of any ultimate power above states, was not defined by an absence of communication and cooperation between the states. Neo-liberalists propose that systems have two dimensions; system and process, where process is provided through cooperation and communication between states (Nye 1988, 249). Through this expansion of definition, IR scholars Robert Keohane and Joseph Nye proposed that communication and cooperation provide an opportunity for states to change their interests (Nye 1988, 249-250). Neo-liberalism further moved from classic liberalism by identifying three causal strands to liberal theory; commercial liberalism, where absolute gains can be made by all states in an open market; democratic liberalism, purporting the pacific affects of republican government; and institutional liberalism, where rules and regulations of international institutions conform the 
interactions of states in the anarchic system (Nye 1988, 246). Neo-liberalists argue that, with the increased ability of states to communicate with each other through international institutions and the norms of state behaviour embedded in these institutions, a reduction in the security dilemma of the anarchic system will result (Nye 1988, 250). Through institutional neo-liberalism, supported by the mutual absolute gains available to all states through commercial neo-liberalism, it is argued that the interest of the states can be changed and cooperation impetus moved beyond self preservation under the security dilemma.

Through the neo-liberal lens, the establishment and ongoing international participation in multilateral international institutions holds substantial benefit to New Zealand as a small state. Without the capabilities of larger states, norm propagations that align with New Zealand's interests through international institutions provide a form of 'norm governance' in the anarchic system; providing protection of New Zealand's sovereignty and its ability to increase its economic capabilities (Thorhallsson 2012, 142). As such, the neo-liberal lens holds substantial explanatory power for New Zealand's foreign policy stance through the post-WWII and Cold War years, and to some extent in the current era of international politics.

Through governments of both of the two major political parties of New Zealand from the end of WWII, commitment to multilateralism has been prominent in foreign policy discourse (Buchanan 2012). Equally, the establishment of free trade agreements, including multilateral trade agreements, has been a mainstay across governments of both major parties (Small 2015). However, the limits of neo-liberal theory alone providing an explanatory framework for New Zealand's actions in the international system are exposed when attempting to use the theory to explain New Zealand's establishment of its nuclear free policy in 1985, and in many of its international actions since that time. Although neo-liberalism allows that norms of international institutions may, with the process of communication and cooperation with other states, alter states' interests, it cannot provide explanation of why a state would change its interests without interaction from other states that support the change. Nor can it explain a state's international interactions that reduce not only its security capabilities but also its opportunities for cooperation and trade with a hegemonic state previously in alliance with the state. Neo-liberalism cannot explain why New Zealand would stand against the US on a position that ended the ANZUS treaty, removing the security umbrella of the hegemon. 
Neither neo-realism nor neo-liberalism provide explanation for a state acting in interests driven by moral imperative or human ethical values, as both traditional theories consider only the state as a unitary actor and allow for neither influence of domestic politics nor national identity in the establishment of state interests in the international system.

\section{Constructivism}

Constructivism provides a more flexible theoretical framework for analysing New Zealand's international political actions in the current global era, through allowance of the social construction of states' interests, and influence of both domestic politics and national identity in state actions in the international arena. Where neo-realism and neo-liberalism argue that state identities and interests are exogenously given, constructivists propose that state ‘identities and interests are endogenous to interaction' (Wendt 1992, 394). Constructivism argues that through the process of inter-state interaction, states acquire identities that also form the basis of a state's interests. That is, states' identities hold a social context and are formed through interaction with other states. Constructivism does not contradict the three part definition of the neo-realist structure of the international system (anarchy, states as like units and the distribution of capabilities of the states (Waltz 1979, 100-101)), but rather adds a fourth layer to the definition of structure; socially constructed structure of identities and interests in the system (Wendt 1992, 401). A state will act towards another state based on the meaning it holds for that state, which has been developed through both that state's selfidentification and the understanding it has of the other state; an identity for the other, which is continuously developed through the other's participation in the international system (Wendt 1992, 407). Consistency of behaviour of a state in interactions with other states over an issue reinforces the expectation of how the state will behave in future interactions, defining the state's identity in the system through norm establishment and reducing the threat to security of other states perceived as posed by the subject state. As such, constructivists allow that the neo-realist's self-preservation is only one institution, or structure of interests and identities, that may exist in an anarchic system (Wendt 1992, 399). The security dilemma need not exist should the interactions of states in the system not lead to a meaning of actions that drives a competitive social interaction, establishing the institution as an inherent security dilemma. 
Constructivism allows an additional flexibility beyond neo-realism or neo-liberalism in explanatory power for states' actions; that the structure of an established institution of identity and interests of states in a system can be changed through socialisation. Conditions for such a change require that both sufficiently high density and regularity of interaction must occur between the states, and 'the actors (states) must be be dissatisfied with pre-existing forms of identity' (Wendt 1992, 414). The change of interactions by New Zealand in the international system following the 1985 nuclear-free declaration, and consistency of standpoint of the state on the issue since this time, indicate a change of state identity reinforced through socialisation, as interpreted through a constructivist lens.

While allowing the ability to change state interests through process, constructivism posits a change of the unit of analysis of the international system from structure, as per neo-realism and neo-liberalism, to 'agent' (Checkel 1998, 326-327). Constructivists focus on the human agents who act on behalf of states, the state's political elites, and allows that these agents have influence on the actions of the state (Burchill 2005, 185-186), within the meaning of the identity and interest institution established for the system.

Differing streams of scholarship have developed under constructivism where the influence of the human agent on state interests is more comprehensively theorised. Of these, the impact of domestic politics on the interests of state elites, and so influence on the state's actions in the international system, are considered a relevant analytical variable in IR (Walt 1984, 42). Within another development of constructivist theory, collective identity of the nation state is argued to bound the interests that can be enacted by the state's political elites. Social identity theory scholarship proposes a number of potential avenues by which collective identity of the nation state can influence actions of states in the international political system.

While scholarship on collective identity has been plagued by what has been termed 'definitional anarchy' (Abdelal et al. 2006, 695), Rawi Abdelal et al propose an analytical framework to define a collective identity that enables comparison of types of identities and promotes coordination between scholars to improve the validity of identity as a variable in research. Abdelal et al's framework defines 'a collective identity as a social category that varies along two dimensions - content and contestation'(Abdelal et al. 2006, 696). Content is effectively what the identity means, and is constituted by four non-exclusive types: constitutive norms, which are the practices and rules of the identity that impose obligations 
on members; social purpose, which are the specific goals and preferences of the group; relational comparisons, which allows the identity to be defined by what it is not; and cognitive models, which are effectively the worldview of the group, or how the members interpret social, political and economic order (Abdelal et al. 2006, 696-699). Contestation is the degree of agreement within the collective identity group of the content of the group (Abdelal et al. 2006, 696). By incorporating contestation into their framework, Abdelal et al allow for the fact that collective identities are fluid and dynamic, and that they are continuously shaped by members through the process of social contestation (Abdelal et al. 2006, 700).

Thomas Risse et al propose that national identity is collective identity defining a social group on the basis of mostly territorial criteria (Risse et al. 1999, 155), and that national identities are linked to sovereignty and statehood, and often incorporate visions of political and social orders. This is congruent with the cognitive model content type of Abdelal et al's framework. Risse et al define nation-state identity as a component of national identity, which can be interpreted as a component of Abdelal et al's cognitive model content type, describing how the group understand state and political order (Risse et al. 1999, 155).

Montserrat Guibernau's definition a nation identity reinforces the territorial component proposed by Risse et al for national identity. She argues that territory combines with the group's consciousness of forming a distinct community with shared culture, past, symbols and traditions to differentiate the nation from other groups (Guibernau 2007, 11). Guibernau's national identity is a collective sentiment based on a belief of belonging to the same nation, with members sharing most of the attributes of the nation that make it distinct, where those shared attributes are usually common culture, history, kinship, language, religion, territory, founding moment and destiny (Guibernau 2007, 11). However, she stipulates that each of these attributes are invoked to varying degrees by members of particular national identities (Guibernau 2007, 11), which agrees with the contestation component of Abdelal et al's framework. Guibernau's work agrees with Abdelal et al by stating that national identities are fluid and dynamic (Guibernau 2007, 11), such that they can be changed through contestation or socialisation.

Guibernau highlighted that state elites can utilise national identity domestically as the most effective tool to achieve national mobilisation (Guibernau 2007, 16-19). This concept of 
instrumentalism in social identity theory scholarship argues that elites invoke shared beliefs within the bounds of the identity definition accepted by the masses in order to achieve their own interests when acting on behalf of the collective identity (Varshney 2007, 282-284; Brown 2004, 281). For state political elites, this can mean that the actions they are able to take on behalf of the nation state in the international arena are bounded by the definition of the national identity, if the elite's political support of the masses is to be retained. A similar theory was proposed by Robert Putnam in his supposition of international negotiations as a two level game, where the first level of an international interaction being negotiated by the state's elite, or central executive, must fall within a 'win-set' that has been ratified at the second domestic level in order for the elite to both retain domestic support and succeed in the international engagement. Putnam notes that 'any leader who fails to satisfy his fellow players at the domestic table risks being evicted by his seat' (Putnam 1988, 434). Putnam argues the domestic influence on international relations covers the gambit of politics, being 'parties, social classes, interest groups (both economic and noneconomic), legislators, and even public opinion and elections' (Putnam 1988, 432). While Putnam's 'win-set' may be narrowed by those domestic influences, it can be argued that, in a robust democracy, the broadest international engagement 'win-set' boundaries will be those that retain the public opinion support and so ensure the domestic position of the negotiating political elite is not challenged following the actions taken in the international engagement. The 'win-set' available to the political elite in the international negotiation will then, at its broadest, be bounded by actions that will not challenge the internalised national identity content relevant in the context, ensuring popular domestic support is retained. In a democratic nation-state, political elites cannot retain support of the masses, and thus political power, if their actions in the international political arena contradict the accepted national identity. As argued by Guibernau, a national identity cannot be imposed by a state's elites on the masses of the state; for a national identity to be internalised across the population, it must be defined by myths, symbols and traditions and language that resonate with the masses (Guibernau 2007, 18). Content of a national identity can be instrumentalised by political elites in order to mobilise domestic support for interests of the political elite (Guibernau 2007, 15-16).

Both Risse et al and Guibernau argue that national identity is a modern phenomenon, enabled by mass communication mechanisms to spread the common language, traditions, myths and symbols of the collective identity (Guibernau 2007, 16; Risse et al. 1999, 155). Guibernau posits that, while elites play a significant role in the creation of national identity, due to their 
ability to influence the institutions that reinforce common language, myths and symbols such as education systems and through their greater access to the media, it is the acceptance and internalisation of this content by the masses that defines the national identity (Guibernau 2007, 18). Abdelal et al identify the most common methodology of measuring of collective identity content and contestation is through discourse analysis and surveys of members of the identity (Abdelal et al. 2006, 702-703). Drawing on Guibernau's argument and Abdelal et al.'s methodologies, this thesis argues that public opinion identifies and determines national identity content and contestation, while elite discourse invoking national identity, including foreign policy discourse, acts only as an indicator of content already popularly internalised by the masses of the national identity.

\section{A Pragmatic Combined Analytical Framework}

Employing analytic eclecticism, it is possible to connect singular theory analysis conducted under the disparate principles of neo-realism, neo-liberalism and constructivism to inform a more comprehensive understanding of contemporary state actions in the international system. While key differences between the fundamental assumptions of the traditional IR theories of neo-realism and neo-liberalism and those of constructivism - state actions driven by the system versus state actions influenced by agents - are incommensurable, separately determined analyses can be pragmatically connected for substantive contexts. Under neorealism and neo-liberalism, political elites in international politics act to achieve the state's interests as driven by the system; either by increasing the material strength of the state in the international system, through a neo-realist lens, or reinforcing multilateral organisations, international norms or trade arrangements that will ultimately increase the material interests of the state, through a neo-liberal lens. Through the addition of the constructivist lens, it can also be argued that, in a non-corrupt democracy, the political elite will act in international engagements in line with popularly internalised national identity characteristics relevant to the context of the engagement in order to retain domestic support, even if those actions do not align with the material interests of the state. It is by identifying the conditions under which the state's actions do not align with predicted action under any one of the three theories within the combined theoretical framework that analytic eclecticism provides greatest explanatory power and practical interest for substantive issues. 


\section{Methodology}

In analysing the actions of New Zealand during its tenure on the UNSC in both 1993-94 and 2015-16, this thesis will employ analytic eclecticism by utilising a combined theoretical framework of neo-realism, neo-liberalism and constructivism, where the latter encompasses agent influence on state action through national identity. The methodology to conduct this analysis will begin by establishing relevant, popularly internalised content of the New Zealand national identity the periods of both the 1993-1994 and 2015-2016 UNSC tenure that are relevant in the international engagements of the country on the UNSC, identifying this content through historical and IR scholarship and foreign policy discourse. As established earlier in this chapter, national identity is argued by this thesis to reside in public opinion, with foreign policy discourse only serving to indicate already mass-internalised national identity content as relevant to the national identity engaging internationally. Public internalisation and degree of prioritisation for the national identity content during each UNSC tenure period will then be argued, through review of relevant primary survey data sources of public opinion. This analysis will define a 'win-set' of relative prioritisation of national identity content for each UNSC tenure period that this thesis argues as bounding New Zealand's political elites' actions in the international political arena. The change in New Zealand's international strategic and economic relationships between the two UNSC tenure periods is also investigated in the discussion of impact on degree of prioritisation of affected national identity content.

Actions that New Zealand could take on the UNSC during both its 1993-94 and 2015-16 tenure to indicate its intent on global issues, and which this thesis will analyse against the established combined theoretical framework, are set out in Chapter V. Scholarship is referenced to assist identification of the actions taken by New Zealand during the 1993-94 UNSC tenure due to limited primary sources for this period. For the 2015-16 period, analysis is conducted by review of available documentation of UNSC meetings, resolutions, voting records, statements and press releases, as well as New Zealand Government press releases, New Zealand Ministry of Foreign Affairs and Trade (MFAT) Ministerial Statements and New Zealand Prime Ministerial statements. News media resources will be utilised where these primary sources can be expanded, most particularly in discussion of New Zealand's alliances with other states over UNSC draft resolutions. 
Through analysis, New Zealand's actions on the UNSC will be determined against the established combined IR theoretical framework as either aligned with pursuit of the state's material interests (neo-realism and/or neo-liberalism) and in line with relevant national identity content established by this thesis (constructivism), or aligned with national identity characteristics only (constructivism only).

Finally, this thesis will compare the findings of New Zealand's actions against this combined theoretical framework of both the 1993-94 and 2015-16 UNSC tenure. Utilising the practical benefits of this analytic eclecticism approach for substantive issues, changes or otherwise in the relative degree that New Zealand's actions were aligned with material interests or national identity only during the two UNSC tenures will then be discussed in relation to identified changes in New Zealand's international strategic and economic relationships in the period between the two tenures. 


\section{Literature Review: New Zealand's National Identity in Historical and International Relations Scholarship}

New Zealand's national identity in academic scholarship is most commonly a discussion of the historical steps of the nation to become independent of its British colonial roots, and the subsequent development of consistent foreign policy characteristics that scholars purport as national identity content. While consideration of collective identity as an explanatory variable in IR scholarship has increased since the 1990s, it is widely acknowledged by scholars that little academic consideration has yet been given to New Zealand's national identity as an explanatory framework in its international actions (Capie and McGhie 2005, 230; Barker et al. 2010, 3-4).

In this chapter, historical scholarship is first reviewed to show the historical construction of the New Zealand self-image through British colonial periods and into self-governance and first independent actions in the international system. Contemporary IR scholarship of national identity influence in New Zealand's international actions is then reviewed, and missing elements this thesis aims to achieve is highlighted.

\section{Historical Establishment of New Zealand's National Identity}

Historian Michael King sets out a comprehensive chronology of the establishment of New Zealand a nation in his Penguin History of New Zealand, identifying key milestones collective identity development through burgeoning nationhood, as Maori and Pakeha (meaning all New Zealand settlers of European origin) collective identities separately developed.

Some 800 years ago, the Maori people travelled and descended from Polynesia to become the first humans to sustain settlement in New Zealand, where centuries of isolation led to the unique Maori culture (King 2003, 13-23). European settlement only occurred after the British circumnavigation and cartographic survey conducted by Captain James Cook in 1770 (King 2003, 74-86). King comprehensively details how the collective identities of the two initial settler ethnicities in New Zealand - Maori and Pakeha - remained separate through the initial European pioneering settlement then British annexation of New Zealand and subsequent establishment as a Dominion of the British Empire in 1907. King outlines that a Maori collective identity was only established when a clear 'other' was found in opposition 
to the British settlers, when the traditional tribal basis of Maori culture had proved inadequate in separate opposition to the existential threat to Maori as a surviving ethnicity, through both conflicts over land as well as introduced disease (King 2003, 144-170). Despite the cultural diversity of the European settlers - majority English and Welsh, with Scottish and Irish in significant numbers then German, French, Scandinavian, Polish and Italian in minor proportions -New Zealand as a colony 'retained a strong 'British' character' through the 19th century (King 2003, 139-140). The colony often referenced itself, and was referenced externally, as 'Britain of the South' or 'Better Britain', being free of the class divide that was seen as a barrier to prosperity in Britain (King 2003, 135, 217).

The signing of The Treaty of Waitangi in 1840 between Maori chiefs and the British Crown is often referenced in historical and political scholarship as the founding document of New Zealand. The Treaty declared that all New Zealand Maori 'cede to Her Majesty the Queen of England absolutely and without reservation all the rights and powers of Sovereignty ... over their respective Territories ...' (Hobson, Busby, and Freeman 1840). Although collaboration with Maori allowed the British colony to grow and begin to economically thrive, introduced disease and land purchase conflicts fed rising resentment in Maori, punctuated in the late 19th century by the New Zealand Wars between Maori and British (King 2003, 170-177). Although the New Zealand Wars ended in 1872, the Maori population declined while booming immigration saw the colony population dramatically increase through to the end of the 19th century (King 2003, 142, 173). Maori population remained approximately ten percent of the total population of New Zealand through the 20th century (King 2003, 207).

Political milestones were also important in the development of a burgeoning national identity. A centralised New Zealand government was first established when New Zealand was a colony, modelled off the British parliamentary system. Maori representation in parliament was established as early as 1867 - a first for inclusion of native peoples of the British Empire (King 2003, 195). A Labour party government elected in 1892, remaining in power for 21 years, instigated substantial labour reforms that were remarkable for the time in the developed world. Establishment of a Department of Public Health, the first of its kind anywhere in the world, added weight to a growing reputation of New Zealand externally as 'the social laboratory of the world'(King 2003, 219). In 1893 New Zealand became 'the first sovereign state in the world to give women the right to vote' (King 2003, 216) and in doing so became 'the most democratic state in the world' (King 2003, 216), as all Maori and 
Pakeha men of eligible age had also been provided the right to vote. The New Zealand political elite at the time believed that these social firsts meant that New Zealand was 'showing the way to the rest of the world' (King 2003, 228), while still being externally regarded as - and its population considering itself as -loyal British subjects (King 2003, 228).

James Belich builds further on the historical content of the New Zealand national identity in his work Myth, Race and Identity in New Zealand, by proposing the devices that enabled the 'us' and 'them' of Maori and Pakeha to be overcome to allow establishment of a bi-ethnic national identity. Belich outlines the European 'myths' that perpetuated in the late 19th and early 20th century that elevated the Maori people in the estimation of British colonists over indigenous peoples encountered in other lands of the Empire. He establishes that different connotations of a European 'savage' myth applied to Maori enabled the British colonists in New Zealand to assimilate elements of Maori culture into their own collective identity. Belich states that in the late 1800 s through to 1920 , the British colonists applied perceptions of stereotypes of Maori as either 'White Savage', meaning perceived as wanting and able to assimilate the European culture and having existing cultural similarities to Europeans, or the 'Grey Savage', meaning that the ethnicity was dying and so the culture was deserving of respect. Belich reinforces that in the late 19th century, New Zealand was considered 'the Britain of the South'(Belich 1997, 13) by both the colonists and Britain, but goes further to propose that it was perceived that New Zealand would in future be better than Britain, due to the colony 'having the 'best blacks''(Belich 1997, 13) of the British Empire and 'treating them best' (Belich 1997, 13) as well as promising economic prosperity (Belich 1997, 13-14). Belich proposes that this Pakeha collective identity content of superiority over Britain altered after economic depression in the late 19th century and early 20th century, and a 'recolonization' occurred that drove the New Zealand colony to re-affirm its affinity with Britain, while still maintaining existing popularly internalised content of superiority. Belich argues that this collective identity drive for 'sameness' to Britain drove New Zealand to prove its affinity by the proportion of military contribution to World War One (WWI), being the greatest per capita of any British dominion (Belich 1997, 14). In parallel, Belich sets out that the Maori collective identity had been slow to move from family and tribal to a single understanding of Maoridom but identifies the burgeoning emergence of a single Maori collective identity from 1850 in response to the European other (Belich 1997, 16). Belich claims a British documentation of Maori history, widely accepted as erroneous, led to a myth 
of Maori as descendent from the ancestors of Europeans - the 'Aryan Maori' myth - which was readily accepted not just by colonists but also by Britain and its scholars. Belich states the Aryan Maori myth allowed the colonists to claim cultural aspects of Maori into the collective identity that allowed distinctiveness in the British Empire without challenging the the racial homogeneity that maintained sameness with Britain (Belich 1997, 16-18). The myth of 'Grey Savage' greatly hastened the process of collecting and assimilating Maori culture into the colonial identity, with belief that Maori neared extinction. Belich states that similar to demonstrating 'Better Britain' content of the New Zealand national identity, war and sport were used by Pakeha to further incorporate Maori Aryanism into the collective national identity. Although a separation of a Maori battalion in New Zealand troops fighting in WWI and a separate Maori rugby team did not align with assimilation, the Pakeha celebration of their achievements were fundamental to the assimilation of the two ethnicities to a single New Zealand national identity (Belich 1997, 19). As the key argument of his work, Belich claims that the Aryan Maori myth bonded Maori and 'linked, distinguished and enhanced them in relation to Pakeha, just as Better Briton and Aryanism served Pakeha in relation to Britain' (Belich 1997, 22).

Belich's framework of myth leading to collective identity formation is powerful in providing explanation of how the bi-ethnic New Zealand collective identity developed. However, Belich's analysis does not extrapolate to provide analysis of any international actions by New Zealand beyond WWI through the lens of the bicultural national identity he establishes.

In Malcolm McKinnon's Independence and Foreign Policy: New Zealand in the World Since 1935, analysis of New Zealand's actions in the international system for 55 years after 1935 is put forward through discussion of the degree of independence demonstrated by the country. McKinnon approaches his analysis through a characteristic of New Zealand's foreign policy that is commonly instrumentalised by New Zealand's political elite - independence. However, McKinnon eschews the relevance of national identity in discussion of IR, stating that 'it did not seem to [him] that the evolution of identity explained foreign policy, even had anything to do with it' (McKinnon 2013, IX). Instead, McKinnon establishes that a culture of independence was established in New Zealand politics due to its origins in the traditions of British governance. McKinnon identifies two types of independence in New Zealand foreign policy for the framework of his analysis - 'independence of interest'(McKinnon 2013, 2) and independence through 'loyal dissent or loyal opposition' (McKinnon 2013, 2). McKinnon 
argues that independence could be a form of dissent if it was a 'progressive critique of an existing pattern' so long as it did not 'challenge its underlying structure' (McKinnon 2013, 3). McKinnon argues that New Zealand's action of independence by dissent in international engagements has its roots in the British parliamentary system, where opposition could challenge the status quo but still remain loyal (McKinnon 2013,3). McKinnon describes his second type of independence as the 'vigorous defence of interests' (McKinnon 2013, 4), and argues that this was deeply embedded in the culture of the British political classes and so internalised by the New Zealand political elite (McKinnon 2013, 4). McKinnon's work then analyses the key actions by New Zealand in the international system from 1935 to 1991 to determine the degree of independence, or not, demonstrated and whether independence of action by the country demonstrated defence of interests or loyal dissent. McKinnon highlights that key changes in the concept of New Zealand's foreign policy independence occurred in the 1960s and 1970s, when New Zealand for the first time went to war not in support of Britain; sending troops to support US action in Vietnam in 1964 (McKinnon 2013, 175). McKinnon highlights that this period marked the end of the Commonwealth phase of New Zealand's foreign policy history, as Britain pulled back from the Asia Pacific region (McKinnon 2013, 201). McKinnon argues New Zealand's decision to support the US action in Vietnam was indication of independence in defence of interests in line with traditional foreign policy, as it sought to ensure a it 'kept a friendly great power on side in the Pacific' (McKinnon 2013, 176). With increasing domestic pressure against involvement in Vietnam as the conflict continued into the 1970s, McKinnon claims that a fundamental change in New Zealand's sense of independence occurred due to perceived changes in New Zealand's circumstances and values, with the country's political elite articulating this through declaration that New Zealand's foreign policy would be self determined, and not initiated by either British or US inclination (McKinnon 2013, 208-209). McKinnon claims this postVietnam period saw a shift in the nature of independence to nationalism, but argues this independence was not new but an affirmation of British historical relations and rallying against what many New Zealanders saw as 'being corralled by the United States' (McKinnon 2013, 203). McKinnon builds on this determination to discuss New Zealand's actions in what he terms 'the ANZUS crisis' of 1984-1986 (McKinnon 2013, 309), where New Zealand declared it would not allow nuclear powered or armed ships to enter its ports, which effectively ended the Australia, New Zealand and United States of America (ANZUS) treaty (McKinnon 2013, 318). McKinnon discusses an anti-nuclear sentiment in the general population of New Zealand as developing from the peace movement post-Vietnam and 
building on the 'anti-tour movement' (McKinnon 2013, 325), supported across the class and political affiliation spectrum of the New Zealand population, against the South African rugby team tour of New Zealand in 1981 while South Africa was under apartheid (McKinnon 2013, 324-327). McKinnon argues that the nuclear free declaration and its popular association with New Zealand's independent foreign policy was a nationalist phenomenon and completely different from the independence framework used for his earlier analysis of New Zealand's international interactions (McKinnon 2013, 334).

McKinnon touches on, but determines not to develop or consider as an explanatory factor, the idea of New Zealand collective identity influencing the actions of the New Zealand political elite in international engagements. He concedes in several points of discussion in the dramatic shift in independence of foreign policy following both the Vietnam war period and the ANZUS crisis that public opinion was a strong, if not primary, driving factor for political elite actions. McKinnon acknowledges a set of values displayed in public support of peace and racial equality movements, concepts of 'other' (notably with the US ), and an internalised acceptance of nuclear free as bi-partisan and non-negotiable in the New Zealand public opinion (McKinnon 2013, 335-336), but does not discuss these through the lens of collective identity.

Conversely, Jock Phillips, in this work New Zealand and the ANZUS Alliance: Changing National Self-Perceptions, 1945-1988, acknowledges significant change in the collective identity of a selection of New Zealanders through the ANZUS crisis (Phillips 1991, 183). Phillips' explains what he terms an attitudinal change in New Zealand from the end of WWII through to the ANZUS crisis as due to 'a new social group obtaining political and media control' (Phillips 1991, 184). Phillips highlights a decline in British influence in New Zealand culture and a rise of national culture, supported by a new generation coming to positions of influence that was educated and 'capable of generating its own norms' (Phillips 1991, 189) for the first time in country's history. Phillips' argument is that the self-image of the nation had moved from the idea the country as 'the [British] empire's finest son' (Phillips 1991, 190) at the end of WWII, to a self-generated idea of how it should act in the international community thanks to pivotal international engagements that challenged New Zealand's historical colonial self-image. Phillip's key moments driving this change reinforce those highlighted by McKinnon. These occurred in the post-Vietnam war period, when New Zealand's security interests became seen as not necessarily aligned with those of its 
traditional Western allies due to its geographical location (Phillips 1991, 192), the peace movement that grew from this, and the anti-apartheid movement that protested the South African rugby team tour (Phillips 1991, 192-193). Phillips argues that the emergence of the educated generation born post-WWII into positions of influence combined with a 'postcolonial yearning for a new nationalism' (Phillips 1991, 194) to drive a change in national self-image. This generation were the influencers in government during the ANZUS crisis (Phillips 1991, 195). While not using the terminology of collective identity, Phillips outlines key content in the regenerated New Zealand self-image of the 1980s; that New Zealand embraced Maori and was a South Pacific nation, being both a 'paradise' that needed to be protected and with changed perceptions of security threats; and that New Zealand was a 'moral example to a corrupt old world' (Phillips 1991, 197). Phillips extrapolates the moral content as a drive for New Zealand, being geographically detached from the rest of the world, to 'nudge the rest of the world in a peaceful direction' (Phillips 1991, 198) and protect the South Pacific from nuclear testing, which Phillips argues led to the declaration of the country as nuclear-free.

Phillips takes pains to ensure he does not suggest that all New Zealanders internalised his view of the national identity (Phillips 1991, 198). Further foundation in survey data to support his national identity content as popularised by the New Zealand public would remove need for this caveat, however his work remains a key understanding of the political elite view of New Zealand's place in the world at this pivotal time in the country's history.

\section{New Zealand National Identity in Contemporary International Relations Scholarship}

It is in more contemporary IR scholarship discussing New Zealand's actions in the international system that identity is overtly considered salient as an explanatory variable. Fiona Barker and David Capie, in their 2010 introduction of articles comparing collective identity political influence between New Zealand and Canada across a range of both domestic and international issues (Identity as a Variable in Canadian and New Zealand Politics), observe the 'remarkable rise of the concept of identity'(Barker et al. 2010,3) in political science since the early 1990s. They acknowledge the difficulty within national identity IR analysis in ascertaining whether political elite actions are bounded by collective identity content or if the content is instrumentalised in international actions to retain domestic power (Barker et al. 2010, 4-5). Particularly relevant to this thesis is the argument by Barker and 
Capie that state adherence to norms for initial purposes of reputation or legitimacy over time embed as identity in international interactions, and can in turn drive actions of the political elite of the state (Barker et al. 2010, 5).

Richard Devetak and Jacqui True take a combined explanatory approach to the comparative analysis of New Zealand and Australian foreign policy divergence in Diplomatic Divergence in the Antipodes: Globalisation, Foreign Policy and State Identity in Australia and New Zealand, interests influenced by different concepts of state self image, or identity, have influenced contemporary differences in foreign policy of the two countries. They claim that, despite shared historical British colonial state identity, the Australia and New Zealand governments' self images have diverged through their different responses to the effects of globalization. Devetak and True deconstruct the approach to globalization by both countries, using traditional IR explanatory framework of neo-liberalism to explain the shared embracement of liberal trade by both nations, and neo-realism for Australia's response to perceived security threat to the state of international terrorism and its support of the USdeclared 'war on terror' post the 9/11 terrorist attacks, obviated in its bandwagoning with its powerful traditional ally (Devetak and True 2006, 246-248, 251-252). Devetak and True comment that New Zealand, in contrast, consider multidimensional global threats to overall state prosperity that include environmental sustainability, regional stability, and human trafficking. The authors argue this drives a different approach to Australia, to support the neo-liberal concepts of multilateralism and enforcement of international rules or norms (Devetak and True 2006, 253-254). They argue that New Zealand's state identity is 'underpinned by its position as an independent and principled player on the world stage' (Devetak and True 2006, 243), expanded by their assessment of its commitment to multilateral institutions and commitment to 'being a good international citizen' (Devetak and True 2006, 248). Where the authors take a key note of the influence of national identity on foreign policy is in consideration of New Zealand's bi-partisan nuclear-free policy, which they argue 'illustrates the power of a norm embedded in national culture to shape identity through foreign policy regardless of the geopolitical and political (and potentially economic) costs associated with it.' (Devetak and True 2006, 254).

Devetak and True's analysis is an excellent step towards a combined theoretical framework analysis of New Zealand's international actions that allows both traditional IR and constructivist theories as explanatory tools. However, while Devetak and True clearly 
outline the different strategic world views held by Australia and New Zealand, they are specific in stating that national identity 'provides no basis for explaining foreign policy variations'(Devetak and True 2006, 243) between the two countries. Instead of attempting to define popularly internalised national identity content, Devetak and True assert their analysis is of how governments (or political elite) perceive their state's social identity (Devetak and True 2006, 243).

Peter Skilling takes a different approach to collective identity and New Zealand foreign policy in his work, The Construction and Use of National Identity in Contemporary New Zealand Political Discourse, discussing political elite instrumentalism of collective identity to achieve state material interests. Skilling analyses the discourse established by the New Zealand Labour government from 1999 to 2008, which he argues was crafted to establish an international view of New Zealand for economic advantage. Skilling argues that national identity can contribute to the legitimacy of political elite, while also establishing that a distinct national identity is vital in the era of globalisation to provide economic competitiveness in global markets (Skilling 2010, 177). Skilling specifically outlines how the Labour government established discourse to promote an economically competitive 'Brand New Zealand' (officially being openness, diversity and tolerance (Skilling 2010, 175)). Skilling outlines government documentation and political discourse, both internationally and domestically, that demonstrates the Labour government's concerted efforts to project a consistent national identity that it attempted to persuade the New Zealand public to internalise, by associating pursuit for economic competitiveness (stressing talent, creativity, flexibility and innovation) with already popularly accepted national identity content of environmental protection, social equality and cultural uniqueness (Skilling 2010, 181-183). Skilling identifies that this process was not successfully accepted by the New Zealand public when elements of New Zealand culture were believed to be exploited for achievement of material interests (Skilling 2010, 185). Where Skilling does not expand his argument is to determine whether the actions of the New Zealand political elite were countering already popularly internalised national identity content, which would not allow for their acceptance by the New Zealand public.

David Capie and Gerald McGhie's Representing New Zealand: Identity, Diplomacy and the Making of Foreign Policy counters what the authors see as historians' and political scientists' vague discussion of identity involvement in foreign policy, in the terms of a 'New Zealand 
national 'character''(Capie and McGhie 2005, 230), by establishing the influence of key content of New Zealand national identity in two specific foreign policy engagements by New Zealand; South Pacific diplomacy in the 1960s and relations with the Soviet Union in the 1980s (Capie and McGhie 2005, 230). Capie and McGhie argue that identity is salient in IR as before a state can determine what its interests will be in international engagements, it must first necessarily determine its identity content to understand 'what kind of state it is, or wants to be, and how it regards others'(Capie and McGhie 2005, 231). Capie and McGhie argue that the way that New Zealand sees itself in the world is dependent on the context of its engagement and specify that, in their discussion of New Zealand's engagements in the South Pacific and with the Soviet Union in the 1960s and 1980s respectfully, they necessarily highlight only some of the ways some content of national identity have influenced New Zealand's actions, due to the 'complexities and fluid nature' (Capie and McGhie 2005, 232) of national identity. Capie and McGhie's establishment of national identity content incorporates the historical elements concurred by King, Belich and McKinnon - a loyal colony of Britain, with foreign policy dictated by this traditional identity - but then more deeply investigate the growing recognition of New Zealand as a Pacific state and the tensions with the traditional collective identity since the 1950s (Capie and McGhie 2005, 232-234). The authors acknowledge that the increase in the Pacific Island population in New Zealand may impact on the New Zealand collective identity and that since 1950 the Pacific is considered more important in New Zealand foreign policy, however they question whether New Zealand has attained a 'Pacific identity' (Capie and McGhie 2005, 235). They argue that despite potential evolving national identity, foreign policy will be influenced by other primary factors, namely trade interests (Capie and McGhie 2005, 235). This argument is supported by assessment of New Zealand's interactions with the Soviet Union in the 1980s, where New Zealand's trade interests were given primacy over traditional national identity content of being a Western ally, as that traditional identity was challenged as New Zealand's interests became seen more and more as different to those of the US and Britain. Capie and McGhie acknowledge the influence of domestic politics to challenging the traditional collective identity, and so influencing foreign policy through the 1980s, naming the ANZUS crisis as the demonstration of New Zealand's limits to its shared identity with traditional Western allies (Capie and McGhie 2005, 236-237). They conclude by asserting that national interests are not determined by material factors, but also driven 'by what kind of country New Zealand is and ought to be' (Capie and McGhie 2005, 238). 
This conclusion is a significant step in acknowledging that an explanatory framework for New Zealand's international actions should necessarily allow for national identity influence. Evidence of popular internalisation of national identity content would provide greater robustness to Capie and McGhie's argument, as would expansion to consider the contemporary degree of key national identity content prioritisation in more recent international actions by New Zealand.

James Headley and Andreas Reitzig's work, Does foreign policy represent the views of the public? Assessing public and elite opinion on New Zealand's foreign policy, provides the most valuable supporting analysis of recent IR scholarship to the investigation conducted in this thesis. Headley and Reitzig argue that New Zealand's robust and open democracy, and small size, means that public opinion can influence foreign policy (Headley and Reitzig 2012, 70). They set out that elements of New Zealand foreign policy and the image the country has of itself in the world has emerged as bi-partisan over three decades up to 2012, including 'adherence to free trade ... a focus on the South Pacific and the wider Asia-Pacific region, a commitment to multilateralism and international institutions... and the promotion of certain principles, such as nuclear disarmament, human rights and democracy' (Headley and Reitzig 2012,71). The authors argue that this bi-partisan consensus reflects and constitutes as stable state identity, and this 'frames the government's outlook and limits its choices' (Headley and Reitzig 2012, 72). The authors surveyed both the New Zealand public and political elite to ascertain the congruence or conflict of how each group sees New Zealand's place in the world and foreign policy goals. The results of the public survey showed public consideration of the importance of the South Pacific (compared to Europe), strong support to promoting human rights abroad, combating global climate change and improving living standards in poor countries - or what could be termed 'moral' foreign policy objectives. What surprised the authors was the strongest publicly-supported foreign policy goal was strengthening the New Zealand economy, while support to global nuclear disarmament and strengthening the UN had lower ranking prioritisation by the New Zealand public. Although more than 60 percent of respondents still rated these as either 'very important or quite important' (Headley and Reitzig 2012, 78-80), the authors claim the results 'cast doubt' (Headley and Reitzig 2012,80) of whether the New Zealand public sees the national image of New Zealand as leading nuclear disarmament or as a leading supporter of multilateralism. In analysis of their survey of political elites, the authors conclude that New Zealand public ranking of foreign policy goals 'is in line with official priorities' (Headley and Reitzig 2012, 83), being not only 
pursuit of economic interests but also 'pursuing certain values, such as promoting human rights' (Headley and Reitzig 2012, 83). The authors caveat that demographic analysis indicates there is not blanket consensus on what they term 'New Zealand's 'international identity' (Headley and Reitzig 2012, 87), and that while elite opinions do not contradict the public, they may be stronger in assertion than is found in public opinion (Headley and Reitzig 2012, 87).

Headley and Reitzig highlight key tension both in public and elite support between valuesbased foreign policy and increasing economic interests. The authors claim this is illustrated by the strong public (and elite) support to New Zealand's free trade agreement (FTA) with China, which can be interpreted to contradict of New Zealand's strong advocacy (public opinion and official) of support of human rights (Headley and Reitzig 2012,73). The work of Headley and Reitzig moves a step closer to providing a combined explanatory theoretical framework for New Zealand's actions in the international system that incorporates both traditional material interest and national identity drivers. Where Headley and Reitzig do not take their work is to formulate their survey results of support to foreign policy into content definition of the New Zealand national identity in international engagements, and then apply that identity content as explanation for specific international actions by New Zealand.

In his work Seeking ontological security through the rise of China: New Zealand as a small trading nation, Jason Young engages the concept of outward facing collective identity, under an ontological security framework, to provide improved theoretical explanatory power for New Zealand's actions in the contemporary era of the country's complex international strategic and economic relationships in his analysis of New Zealand's interactions with China in the last three decades. Questioning the different approach taken by New Zealand in engagements with China through its recent meteoric economic rise from those of other small Western democracies, Young argues pursuit of material interests under traditional IR theories provides inadequate explanatory power as New Zealand's approach to the growing dilemma of relationships with both China and the US differs markedly from that taken by Australia (J. Young 2017, 515). Young instead argues that the actions taken by New Zealand can be better be explained as the New Zealand political elite's pursuit of ontological security, being the security of the self formed and reinforced through routinized relationships (J. Young 2017, 514-515). Young argues that New Zealand's political elite engaged with China in a manner that sought to reinforce their sense of shared collective identity, argued by Young as 
national identity, of being a small trading nation. Young argues that New Zealand's outward facing identity of being a small trading nation underwent existential crisis in the 1960s and 1970s when its trade links with Britain were dramatically reduced, driving the New Zealand political elite to take actions that would reinforce this collective identity. New Zealand's turn to China for trade and its interactions with the nation since are explained as New Zealand's political elite seeking routines of interactions that 'reaffirm their identity as a small trading nation that closely identifies with the liberal international order' (J. Young 2017, 523). Young names one other New Zealand outward facing identity as being 'a good international citizen', and claims this identity did not undergo crisis due to ongoing interactions with likeminded liberal democracies. Young argues under his ontological security framework that the lack of crisis for the 'good international citizen' identity explains why New Zealand's political elite framed engagements with China as being in accordance with New Zealand's support of international order (J. Young 2017, 524).

Young's work provides expanded theoretical explanatory power for New Zealand's interactions with China in the contemporary era from that offered by traditional IR theories, through the allowance of agent influence on state action. However, Young's definition of national identity content driving political elite actions is limited to only two elements of content - being a small trading nation and a good international citizen. This simplifies Young's analysis and reduces the practical application of his findings for substantive complex engagements with China by political practitioners. Young identifies what he terms 'national identity' from political elite foreign policy discourse but does not consider whether this identity content has been internalised by the New Zealand public. By simplifying national identity under his ontological security framework as the sense of self held by political elite only, Young does not allow for the influence of domestic politics on the actions of the New Zealand political elite that would be provided by broader national identity content definition supported by evidence of internalisation by the New Zealand public. Young also readily dismisses traditional IR theories as being inadequate in explanation of New Zealand's interactions with China. By employing analytic eclecticism, and analysing actions by New Zealand using both his ontological security framework and traditional IR theory lenses, Young's analysis could also realise the benefit of identifying substantive contexts where his ontological security framework provided explanation when New Zealand's actions contradicted those actions predicted under traditional IR theories. 
This thesis provides a step forward in New Zealand foreign policy IR scholarship by employing analytic eclecticism, through a combined analytical framework, to provide enhanced explanatory power for New Zealand's actions in the complex contemporary era of international interdependence. In employing analytic eclecticism, this thesis provides the benefit of analysis of national identity influence on political elite actions, under constructivism, alongside analysis of pursuit of the state's material interests, under traditional IR theories, to provide explanation for New Zealand's actions on the same substantive issues during two tenures on the UNSC. Under analytic eclecticism, this thesis then provides the pragmatic benefit of allowing connection of analysis under separate theories to enrich explanatory power. Most significantly, this thesis provides the benefit of identifying the substantive context where New Zealand's actions during the two different UNSC tenures were counter to those predicted by traditional IR theories as being in pursuit of material interests, but can be explained as aligned with popularly internalised national identity content under the constructivist lens. This substantive context identification ensures this thesis advances New Zealand foreign policy IR scholarship, by providing practical interest to both New Zealand foreign policy IR scholars and New Zealand's political practitioners.

This thesis also provides a further step to existing scholarship of national identity in New Zealand foreign policy IR by defining content of the New Zealand national identity that was relevant to the country's international engagements during both its tenures on the UNSC in 1993-94 and 2015-16, while also providing evidence of those identified characteristics as popularly internalised by the New Zealand public and the degree to which each national identity content was prioritised by the public during each period. These established 'winsets' of relative prioritisation of New Zealand national identity content are then used within the combined theoretical framework analysis set out in Chapter V of this thesis to explain actions of New Zealand during its UNSC tenures, in combination with traditional IR theories. This benchmarking definition of national identity content using Abdelal et al's analytical framework, and definition of national identity as residing in public opinion, allows future comparative research to be conducted on national identity influence on New Zealand's actions in the international arena, enhancing the utility and validation of national identity as an analytical variable in New Zealand foreign policy IR scholarship by removing the definitional anarchy for New Zealand national identity which exists in extant scholarship. 


\section{New Zealand's National Identity Content and Internalisation}

As set out in chapter II, this thesis argues that national identity resides in the opinion of the masses of the nation state, and so argues that political elite discourse that invokes national identity can only successfully do so, and retain domestic support, for national identity content that has already been popularly internalised by the members of the national identity. Under this standpoint, this thesis argues that New Zealand foreign policy discourse relating to the New Zealand sense of self in the international system identifies national identity content that is either popularly internalised by the New Zealand public or is not contested by the public as it does not counter other popularly internalised national identity content.

In this chapter, New Zealand national identity content relevant to the New Zealand sense of self in the international system is first identified from scholarship and foreign policy discourse. The acceptance by the New Zealand public of this content as included within the national identity and its degree of internalisation, or prioritisation, by the public is then ascertained for the periods of 1993-94 and 2015-16, via review of relevant public opinion surveys. New Zealand national identity content is defined under the analytical framework put forward by Abdelal et al. as set out in Chapter II, being constitutive norms (historical, cultural, territorial), social purpose (moral, political), cognitive model (worldview) and relational comparisons (what New Zealand is not). The relative prioritisation of national identity content during each tenure period is then utilised in Chapter V as the 'win-set' of national identity content in the constructivist element of the combined theoretical framework in analysis of New Zealand's actions on the UNSC in 1993-94 and 2015-16.

This chapter in no way exhausts the definition of the New Zealand national identity, but attempts to define the content that New Zealanders perceive as defining the nation state in the international arena. As such, substantial cultural and relational content of the New Zealand national identity that many New Zealanders identify with are not discussed in this thesis.

\section{Constitutive Norms: Historical, Cultural and Territorial Identity Content}

\section{Historical British Colony}

As clearly established in Chapter II, New Zealand's historical identity as a loyal British outpost was challenged as national identity content through the period following the Vietnam War, catalysed by Britain's retreat from the Asia Pacific region (McKinnon 2013, 325) and its enrolment in the European Economic Community (EEC) (later EU) in 1973 (Patman 
2005, 8). Prior to 1973, Britain had been New Zealand's main export market and, while it remained the fourth largest destination for New Zealand exports immediately after 1973 (as final destination inside the EU), it was this point in history where New Zealand looked for new trading partners, most notably in the US, Australia and Japan (Patman 2005, 8).

In 1992 the EU was the third largest export market for New Zealand (Bowman and Conway 2013, 2), with Britain the majority final destination for New Zealand goods (Taonga n.d.). By 2012, the EU as an export market for New Zealand had dropped to fourth behind Australia, China and other Asia (Bowman and Conway 2013, 2), with the UK remaining the largest market for New Zealand inside the EU (New Zealand Ministry of Foreign Affairs and Trade n.d.). Political elite discourse in 2017 states that New Zealand 'has an important relationship with the UK based on our shared history, strong people to people links, common values and interests, and ongoing cooperation at all levels of government' (New Zealand Ministry of Foreign Affairs and Trade n.d.). But how relevant was the British connection to New Zealanders during both 1993-94 and 2015-16 UNSC tenures?

New Zealand public prioritisation of historical British colonial national identity content in the 1980s (leading into the campaign for the 1993-94 UNSC tenure) can interpreted as low. In a survey of relative importance of countries to New Zealand in 1984, 35 percent of the New Zealanders surveyed believed that Britain was important to New Zealand, behind Australia (65 percent), the US (58 percent) and Japan (44 percent). When asked if Britain would hold future importance for New Zealand, this dropped to only 15 percent (Watts 1991, 145). As trade and strategic interactions with the UK remained constant or declining through the 1990s (Patman 2005, 8), it is argued that this low prioritisation of British colonial national identity content can be extrapolated for the 1993-94 period.

For the 2015-16 UNSC tenure, British colonial national identity content was determined to hold moderate prioritisation by the New Zealand public. A survey of national identity affiliation of New Zealand residents in 2014 showed that 48 percent had an affiliation with New Zealand only. In total, 76 percent identified as mainly or only affiliated with New Zealand and 21 percent were affiliated with New Zealand and one other country, with 31 percent of that 21 percent having affiliation to Britain -6.5 percent of the total surveyed (Research New Zealand 2014, 3-5). The survey sample demographic reflected the 2013 New Zealand census results (Research New Zealand 2014, 2), with 25.2 percent of the New 
Zealand population born oversea and 26.5 percent of that number (6.7 percent of total population) were born in the UK or Ireland (Statistics New Zealand n.d.). In the 2017 Kiwimeter survey, 51.4 percent of more than 220,000 respondents slightly or somewhat agreed that 'New Zealand's British heritage should be central to its national identity' (Osborne, Lees-Marshment, and van der Linden 2016, 47), and a further 17.2 percent strongly agreed with the statement (Osborne, Lees-Marshment, and van der Linden 2016, 47). This relatively high level of affiliation with British heritage, markedly higher than the proportion of the population who were born in Britain would have predicted, implies that this British history content of the New Zealand national identity was moderately internalised by the majority of the New Zealand public during the 2015-16 UNSC tenure.

\section{Western Ally}

As set out in the historical scholarship review in Chapter II, New Zealand's strong allegiances to powerful Western allies including the US and Britain established through WWI and WWII did not ensure New Zealand's continued faithful following in international engagements after the Vietnam War and establishment of a nuclear-free policy in 1985. While foreign policy independence is discussed later as a worldview content, the Western ally content of the national identity is considered separately.

Political discourse through the late 1980s and into the 1990s re-iterated that New Zealand's foreign policy was breaking out from under traditional allies (R. Alley 1984, 18). In 1990, a newly elected National government attempted to initiate closer ties to the US through the 'olive-branch' commitment of medical personnel and military air transport to the US-led multi-national force in the 1990-1991 Iraq war (Cudworth 2002, 154-155). Political discourse in the 1990s articulated a desire to return to the folds of the Western allies, with cautious caveats of independence included, potentially to retain public support for independence from the US established during the ANZUS crisis. While acknowledging and supporting the improved defence relationships with traditional allies in 1991, Foreign Minister Wayne Cooper made the following statement:

'It's patently obvious that the interests of small countries like New Zealand lie in the direction of collective security. So yes, we are rejoining the Western camp, and we're doing it on our terms.' (McKinnon 2013, 331) 
During its 1993-1994 UNSC campaign, New Zealand stressed that it was a friend but not an ally to all the UNSC P5 (including the US and UK), and was neither a member of NATO nor of the EU (O'Brien 2015, 8). So what was the New Zealand public's degree of affiliation as a Western ally leading up to the 1993-94 tenure? In 1984, a public survey of relative future importance of major Western allies to New Zealand showed decreases by almost 20 percentage points from the 1984 level of importance for the US, and more so for the UK. Australia's future importance to New Zealand was seen as significantly higher than that of the US and UK, considered most important in future by 48 percent of respondents. For countries that New Zealand had the most in common, Australia ranked highest with 79 percent, Britain at 37 percent and the US only 14 percent (Watts 1991, 144-145). It is concluded that in this period after the ANZUS crisis, New Zealanders gave low priority to their traditional Western ally national identity content. However, potentially higher priority may have been given to the Western ally content in this period in a context where New Zealand's alignment with Australian was possible, separate from the US or UK.

The official foreign policy intent towards traditional Western allegiances in the period between the 1993-94 and 2015-2016 UNSC tenures was cautious, potentially to retain domestic support, but in latter years leant towards positive. The New Zealand Labour government demonstrated measured support to the US-led 'war on terror' following the 2001 9/11 terrorist attacks in. Military support (albeit limited) was contributed to the US-led, British-supported hunt for Al Qaeda perpetrators in Afghanistan from 2001, without UNSC resolution (Patman 2005, 14). However, in 2003 the Labour government firmly held that they would not support the use of force in Iraq without UNSC resolution and did not support the US and UK invasion (Patman 2005, 14), although it was supported by New Zealand's closest international partner and fellow traditional Western ally Australia (Devetak and True 2006, 252). In the early 2000s the Labour government also made it clear that although its close economic relationship with Australia was fully supported, New Zealand and Australia were not a 'single strategic entity' (Patman 2005, 12).

Key strategic relationship changes between New Zealand and the US occurred in the fiveyear period before the 2015-16 UNSC tenure. Intelligence sharing with the US was resumed in 2009 (Watkins 2014a), and the two countries signed the Wellington Declaration in 2010, in which the US and New Zealand are declared to have a 'strategic partnership'(Ministry of 
Foreign Affairs and Trade 2010) committing to 'joint co-operation'(Ministry of Foreign Affairs and Trade 2010) and 'a partnership for the 21 st century that is flexible, dynamic, and reflects our fundamental beliefs and aspirations' (Ministry of Foreign Affairs and Trade 2010). The Washington Declaration of Defence Co-operation was subsequently signed by New Zealand and the US in 2012, stating a 'shared commitment to a stable and peaceful Asia-Pacific region' (New Zealand Government and United States of America 2012) and 'closer bilateral defense and security cooperation' (New Zealand Government and United States of America 2012). The declaration ensures no inference of a return to the ANZUS treaty (Ayson 2013, 346). In 2012, the US announced the lifting of a 25-year ban on New Zealand military ships docking at US ports (New Zealand Government 2012) and in 2016 the first US military vessel in 33 years was approved by the New Zealand Government to enter a New Zealand port (A. Young 2016a). The New Zealand public's opinion was split over this renewed defence relationship, with an opinion poll in January 2016 showing that while 50.2 percent believed the US ship visit was a positive step, 29.4 percent saw it as negative and 14 percent viewed it as a victory for, or US concession to, New Zealand's nuclear-free policy. In April 2017, in a public opinion poll on whether New Zealand should follow the US into military action in Syria, 91 percent said no (1NEWS 2017). This polling occurred shortly after the conclusion of New Zealand's 2015-16 tenure, and followed public reporting of Syrian President Assad's forces use of chemical weapons on civilians and the US retaliatory missile strike on Syrian government facilities. It can be extrapolated that even the humanitarian offences of the Syrian government would not invoke the New Zealand public to support following the US into military action. New Zealand public opinion of Australia remained strong in the period of the 2015-16 UNSC tenure, with 85 percent rating Australia as the most important country for New Zealand's future in a 2014 public survey (Asia New Zealand Foundation and Colmar Brunton 2015, 5). With the EU (including the UK) coming in third and North America (the US and Canada) fourth in this public ranking, it is argued that the Australia New Zealand Army Corps (ANZAC) connection to Australia established in shared battles in WWI was held in higher priority by the public than the Western ally national identity content. This is supported by a 2013 survey of over 4,000 New Zealanders, where 77 percent believed WWI was important in developing New Zealand's national identity, and 85 percent believed Australia was important to New Zealand's history (Colmar Brunton 2013, 17-19). However, there was a strong emphasis from the New Zealand public of differentiating the country's identity from Australia in this period. This is potentially explained by the growing interpretation, both domestically in Australia and internationally, 
that the Australian foreign policy is no longer independent and the country 'blindly follows' (Ludlam 2016) the US' direction in international affairs (Ludlam 2016). This clear disagreement with New Zealand's national identity content for independence outlined later in this chapter is arguably part of the explanation for why 65 percent of the New Zealand public surveyed in 2008 approved strengthening of New Zealand's separate identity, compared with 51 percent in 1994 (Headley and Reitzig 2012, 77). This desire to differentiate from Australia is argued to counter the impact on the Western ally national identity content of strong identification of the New Zealand public with its historical ANZAC relationship with Australia. It is argued that the combined public opinion and affinity with the US, UK and Australia resulted in low prioritisation of the Western ally national identity content by the New Zealand public during the 2015-16 UNSC tenure.

\section{Bicultural and Multicultural}

As set out in Chapter II scholarship review, self-image of New Zealand as a bicultural Maori and Pakeha state has early genesis in settler adoption of Maori cultural elements to establish a unique collective identity as a British colony. However, biculturalism was arguably internalised through the latter period of the 20th century, officially illustrated by the 1987 Maori Language Act establishing Maori as the second official language of New Zealand (New Zealand History n.d.), and by the New Zealand Government's settlement of Treaty of Waitangi claims by Maori from 1985 with the establishment of the Waitangi Tribunal (New Zealand Parliamentary Library 2006, 1). In 1994, a survey of the New Zealand public found 86 percent believed that Maori culture was important to the New Zealand national identity (New Zealand Ministry for Culture and Heritage 2008, 10). In 2008, 90 percent of New Zealanders held Maori culture as a key element of national identity (New Zealand Ministry for Culture and Heritage 2008, 10). In comparison, in the 2016 New Zealand General Social Survey (NZGSS), Maori culture ranked seventh in a list of the defining characteristics of New Zealand. However, 75.3 percent of more than 220,000 respondents to the 2017 Kiwimeter survey agreed that 'Maori culture is something that all New Zealanders can take pride in, no matter their background' (Osborne, Lees-Marshment, and van der Linden 2016, 47). It is assessed that bicultural national identity content was strongly internalised by the New Zealand public during both the 1993-94 and 2015-16 UNSC tenure periods. 
It can be argued that the New Zealand national identity established strong internalisation of multicultural content for the 2015-16 UNSC tenure period. Significant changes in the ethnic population proportions in New Zealand occurred between the early 1990s and 2015 due to immigration. The changing ethnic demographic of the New Zealand population has been the subject of psychological academic scholarship investigating impacts on New Zealand national identity (Sibley, Hoverd, and Liu 2011), however IR scholarship of these ethnic population demographic changes to New Zealand's international interactions remains limited. However, some scholars do acknowledge a likely impact on national identity and potentially foreign relations from increasing communities in New Zealand with Pacific Island and Asian connections (Patman 2005, 8). In the 1991 Census, 83 percent of the New Zealand population identified as Pakeha/European, 15 percent identified as Maori, 6.6 percent as Pacific peoples, and 6.7 percent identified as Asian, with 20 percent of the population born overseas (Statistics New Zealand 2002). In the 2013 Census, European ethnic proportion of the New Zealand population had dropped to 74 percent and Maori to 14.9 percent while Asian ethnic proportion rose to 11.8 percent and those identifying as Pacific peoples to 6.9 percent (Statistics New Zealand n.d., 6), with 25.2 percent of the population born overseas (Statistics New Zealand n.d., 19). In the 2016 NZGSS, multiculturalism received the same ranking as Maori culture in the characteristics that defined New Zealand, showing a strong progression to internalisation of multiculturalism as New Zealand national identity content (Statistics New Zealand 2017, 12).

\section{A Pacific State}

The demographic shift outlined in New Zealand's population may represent a greater affiliation of the New Zealand population to the Pacific in 2015-16, as supported by a 2012 public survey. When members of the public were asked which regions of the world New Zealand should pay most attention, the South Pacific was named most important (by 78 percent of those surveyed) with Asia second (46 percent), both significantly ahead of Europe and North America (31 and 30 percent respectively) (Headley and Reitzig 2012, 75-76). While no direct capture of public opinion on whether New Zealand is a Pacific state can support this claim, the New Zealand government declared this status internationally in their campaign for the 2015-16 UNSC seat. In campaign documentation provided to all voting UNGA states, the New Zealand government promised to 'bring a fresh perspective to the Security Council, drawing on our multicultural, Asia-Pacific identity' (New Zealand 
Government 2013, 2). New Zealand media coverage of the successful 2015-16 UNSC campaign regularly relayed back to the New Zealand public the strengths invoked by New Zealand political elite in the campaign, of bringing integrity, independence and innovation to the council, but did not detail the declaration of Pacific national identity content by the New Zealand government (New Zealand Herald 2014; Watkins 2014b). The degree of public internalisation of New Zealand as a Pacific state cannot be drawn from this political elite discourse. However, it can be fairly assumed that all New Zealanders are well aware of the geographically isolated location of New Zealand in the South Pacific. It is argued that geographic location, the degree of importance applied by the New Zealand public to the South Pacific region and the increasing Pacific ethnic proportion in the New Zealand population combine such that the Pacific content of the New Zealand national identity was moderate to strongly prioritised at the time of the 2015-16 UNSC tenure.

In comparison, in the government campaign for the 1993-94 UNSC tenure, 'New Zealand emphasised its small state credentials, Pacific interests, and good UN standing' (R. M. Alley 2007, 17). In a survey of the most important regions to New Zealand's future in 1984, AsiaPacific was rated as having only 20 percent importance by members of the New Zealand public (Watts 1991, 145). Although the Pacific population proportion was similar in the early 1990s to 2013, it is argued that generally the New Zealand public applied low priority to the Pacific national identity content in 1993-94.

\section{Social Purpose: Moral and Political Identity Content}

\section{Nuclear-Free}

Established as a key point in New Zealand's history and foreign policy, legislated in 1987 by a Labour government and with bi-partisan commitment to the policy expressed since 1990 (McCraw 2000, 3), New Zealand's nuclear-free policy is recurringly invoked by political elite as national identity content. In 2007, Labour Prime Minister Helen Clark claimed of the nuclear free policy:

'[it] has become an accepted part of New Zealand's identity.

Politicians tamper with it at their peril. It is a cornerstone of our independent foreign policy.' (Clark 2007).

The bi-partisan consensus continued with the National government elected under John Key in 2008, stating his 2010 address to Parliament: 
'The Government will continue to commit to an independent foreign policy... This includes being an important voice in the nuclear nonproliferation arena.'(Key 2010b, 13)

On the occasion of the 2016 first US military ship visit to New Zealand in more than 30 years, the New Zealand Foreign Minister McCully confirmed that New Zealand's position on its nuclear free policy 'had not changed' (A. Young 2016a).

In the late 1980s, it is clear that the New Zealand public strongly prioritised the nuclear free policy as national identity content, and that this support only grew with time. The New Zealand public's nuclear-free sentiment recorded in the late 1980s included not just domestic nuclear ban, but also strong desire for a global halt to nuclear arms proliferation. In a 1986 survey, more than 90 percent of the public questioned opposed any weapons of mass destruction, including nuclear, being stationed in New Zealand, and 73 percent wanted New Zealand's own defence capabilities to be nuclear free. In 198552 percent approved of the nuclear ship visit ban, but by 1989 after the breakdown of the ANZUS alliance, 63 percent supported the ban of nuclear ship visits (Watts 1991, 154-156). It can be readily extrapolated that this national identity content remained strongly prioritised for the 1993-94 UNSC tenure. Indeed, with the resumption of French nuclear testing in the South Pacific in 1995 (Hawkins 2003), it is argued that the nuclear-free national identity content gained even greater priority through the 1990s.

It is argued by scholars that, with global progress in establishment of international norms of the illegality of nuclear weapons and the rise of other global concerns such as terrorism and climate change, the nuclear free national identity content is no longer strongly prioritised by contemporary New Zealanders (Boyd 2016, 19; Headley and Reitzig 2012, 80). In 1996, the International Court of Justice ruled that threat or use of nuclear weapons in self-defence would be contrary to the laws of armed conflict (Boyd 2016, 11) and the Comprehensive Nuclear Test Ban Treaty was signed by the overwhelming majority of UN member states (United Nations Office for Disarmament Affairs n.d.), with New Zealand's political elite declaring both a victory for the country's 'anti-nuclear crusade' (Boyd 2016, 11, 19). A 2012 public survey on the importance of New Zealand foreign policy goals saw only 67 percent believe contributing to nuclear disarmament was important, the second lowest rated policy goal, far behind most important rated goals of strengthening New Zealand's economy (97 
percent), promoting human rights abroad ( 86 percent) and combating climate change (79 percent) (Headley and Reitzig 2012, 78-79). This is supported by two further surveys indicating only moderate priority on nuclear-free identity. In 2014, when members of the public were asked what made them proud of New Zealand, 21 percent were proud of New Zealand's Principles (with its nuclear free policy bundled with free speech, democracy and being first to give women the right to vote), ranking third behind pride in general sporting achievements (48 percent) and the All Blacks (28 percent) (Research New Zealand 2014, 14). In public opinion poll of the US military ship visit in 2016, only 29.4 percent were against the visit while 16 percent approved on the basis of it as a success of New Zealand's nuclear free policy (New Zealand Herald 2016a). With no direct question on nuclear free identity, and as the visit was widely reported by media as not threatening New Zealand's nuclear-free policy (Small 2016), it is not possible to extrapolate these numbers into strong prioritisation of nuclear free national identity content. It is therefore argued that for the 2015-16 tenure, the nuclear free national identity content held moderate priority to the New Zealand public.

\section{A Principled, Good Global Citizen}

As set out in Chapter II, the idea of New Zealand being a 'good global citizen' has strong basis in its early labour reforms, voting rights for women and treatment of Maori, where New Zealand considered itself as setting an example to the rest of the world. Through the strong peace movements in the post-Vietnam War period and establishment of the nuclear free policy, New Zealand continued this principled national self-image into the late 20th century. These historical actions have contributed to the establishment of a set of what are recognised as New Zealand's defining moral values; equality, fairness and honesty (Taonga n.d.). In the same moral drive that saw New Zealanders protect its South Pacific neighbourhood against nuclear testing through to the 1990s, in the era of globalisation New Zealand is driven by moral principles to fight global climate change (Headley and Reitzig 2012, 73). With the bicultural identity content prioritisation strongly reinforced by generally successful Treaty of Waitangi claims settlement with Maori, it is argued that New Zealand sees itself uniquely experienced to support ethnic conflict resolution around the world (Patman 2005, 10). Internalised societal equality values, with a genesis in the early establishment of a government welfare system, is argued to morally drive New Zealanders' support to provide humanitarian assistance for conflict or disaster affected people around the world. 
New Zealand's political elite often invoke the national identity content of being a good global citizen and the country's moral values. In the 1993-94 UNSC tenure campaign, the New Zealand government emphasised the country's 'good UN standing' (R. M. Alley 2007, 17). In the campaign for the 2015-16 UNSC tenure, New Zealand campaigned that it would bring integrity and independence to the council, and reinforced it was as 'fairminded' (New Zealand Government 2013,6) and 'committed to fairness at the UN and... an inclusive, transparent and effective Security Council' (New Zealand Government 2013, 2). But how true did these values resound as national identity for the New Zealand public during the two UNSC tenure periods?

As established, the 1993-94 tenure fell in the near period of New Zealand establishing a morally driven nuclear free policy, with resounding public support that only grew through the 1990s. A survey in 1994 found that only 14 percent of the surveyed New Zealand public favoured an increase in the level of aid that New Zealand gave to less wealthy countries, however a seven percent increase from a survey in 1976 (63 percent up from 56) was found in positive responses that provision of aid contributes to world peace (Headley and Reitzig 2012, 82-83). Moral values were also demonstrated in the New Zealand public's strong support to peacekeeping around the globe, although only under multilateral sanction. In 1994, 88 percent of the New Zealand public surveyed supported the country's contribution to UN peacekeeping (Headley and Reitzig 2012,81). While no further public survey data is available in this period, it is argued that extrapolation is possible of the indicated strong public moral support for these three issues to conclude that the national identity content of being a principled, good international citizen was strongly prioritised by New Zealanders in 1993-94.

For the 2015-16 UNSC tenure period, substantially more public opinion data is available. In a 2012 survey, the New Zealand public ranked strengthening the New Zealand economy as almost 30 percent more important as a foreign policy goal than promoting human rights abroad and combating climate change, and almost 40 percent more important than improving standards of living in poor countries or contributing to nuclear disarmament (Headley and Reitzig 2012, 78). As previously discussed, in the 2014 NZGSS only 21 percent of the surveyed public were proud of New Zealand's Principles (being nuclear free policy, democracy, freedom of speech and giving women the vote), compared to 48 percent being proud of sporting achievements (Research New Zealand 2014, 14). However, in a dramatic 
shift in only two years, the 2016 NZGSS returned that 9 out of 10 members of the New Zealand public rated freedom, rights and peace and New Zealand's natural environment as the most important characteristics in defining New Zealand, with sporting achievements ranked sixth (Statistics New Zealand 2017, 12). In 2017, 73.7 percent of over 220,000 respondents to the Kiwimeter survey somewhat or strongly agreed that New Zealand had a unique set of values that distinguish it from the rest of the world, and 50.4 percent agreed to some level that while New Zealand is not perfect, its values are superior to others.

Supporting the egalitarian content of New Zealand's defining identity values, 76.8 percent of respondents to the Kiwimeter survey somewhat or strongly agreed that the wealthy are obligated to help those in need. Indicating the translation of the domestic social egalitarianism value into international national identity moral content, 77.1 percent agreed to some degree (28.3 percent strongly) that New Zealand should participate in humanitarian intervention efforts abroad. (Osborne, Lees-Marshment, and van der Linden 2016, 47). This social equality value is evident in the growing multiculturalism in the last decade. High levels of tolerance were indicated in the 2008 NZGSS in New Zealanders' attitude towards ethnic diversity, with 83 percent agreeing different ethnicities in New Zealand was a good thing (Statistics New Zealand 2011, 5). In an era where attitudes to immigration in nations around the world have become resoundingly negative, New Zealand public opinion was recorded in a 2015 global poll as positive and inclusive towards immigrants (International Organization for Migration 2015). It is argued for the 2015-16 UNSC tenure period, tolerance of immigrants and ethnicities remains a key element of the defining moral values of the national identity content.

Tolerance also translates into low public support for the enforcement of democracy on other states. New Zealand has a strong history of supporting UN-sanctioned peacekeeping missions to maintain global peace and stability (New Zealand Government 2013, 2-4). However, as shown in the refusal to support the US-led invasion of Iraq in 2003, the New Zealand government does not support unilateral military action that aims to enforce regime change to achieve democratic governance, instead supporting multilateral determination of need for force for humanitarian reasons or to ensure global peace and stability (Patman 2005, 14). During the 2015-16 UNSC tenure, national identity content of being a global peacekeeper was strongly prioritised by the New Zealand public, with 87 percent approving New Zealand's support to UN or regionally-endorsed peacekeeping missions and 84 percent approving New Zealand Defence Force (NZDF) deployment to prevent abuses of human 
rights in a 2012 survey (Headley and Reitzig 2012, 81). Conversely, only 39 percent of those surveyed supported NZDF deployment overseas to establish democracy in undemocratic countries (Headley and Reitzig 2012, 81). Although in the 2015-16 UNSC tenure period New Zealand had reduced its numbers of NZDF personnel supporting UN peacekeeping missions due to government concerns on UN practices affecting safety of deployed personnel (New Zealand Herald 2017), the 2016 NZGSS still indicated that 'freedom, rights and peace' (Statistics New Zealand 2017, 12) were the most important defining characteristics of New Zealand to the public.

This resurgence of internalisation of the principles or values defining the New Zealand national identity clearly indicated that this moral national identity content of being a principled, good international citizen was strongly prioritised by the New Zealand public during the 2015-16 UNSC tenure.

\section{Cognitive Model: World View Identity Content}

\section{Independence}

As set out in Chapter II, New Zealand's independence of foreign policy has been repeatedly invoked in political discourse, punctuated by its emphasis in the campaigns for both the 1993-94 and 2015-16 UNSC tenures (R. M. Alley 2007, 17; New Zealand Government 2013). Its prominence in speeches and media interviews by political elite has been a mainstay for decades, and has not received documented public rebuff. Indeed, the New Zealand government decision not to follow the US and UK in the 2003 Iraq invasion was widely supported by the New Zealand public (New Zealand Parliamentary Library 2003, 1), and can be seen as enactment of the much declared independence in international actions, with the government not bowing to pressure from the US to join the military action (Radio New Zealand 2015). The pressure applied by the US to the New Zealand government during the ANZUS crisis to retract its nuclear-free policy was widely considered by the New Zealand public at the time as 'bullying tactics' (McKinnon 2013, 332), illustrated by the marked increase in public support for the nuclear ship ban after the breakdown of US-NZ negotiations to retain the ANZUS alliance in 1986 (Phillips 1991, 155-156). When this public opinion against conceding to the wishes of the US is combined with the New Zealanders' reduced association with Britain in the 1990s discussed earlier in this chapter, it 
is concluded that New Zealand's independence in international actions was strongly prioritised as national identity content for the 1993-94 UNSC tenure.

Changes in strategic relationships with not just the US but also China - both P5 members of the UNSC - occurred in the early 21st century. The US's engagement with New Zealand increased following its 'pivot' to the Asia-Pacific region, outlined by Hilary Clinton as the US' region of focus for diplomatic, economic and strategic investment during 'America's Pacific Century' (Clinton 2011). This regional US investment was strongly indicated in 2008 when the US acceded to join negotiations of the Trans-Pacific Partnership (TPP) agreement, of which New Zealand was a founding state (Ayson 2013,353). Although newly-elected US President Donald Trump removed the US from the TPP in early 2017 before it could be endorsed by the US Congress (Baker 2017), during the 2015-16 UNSC tenure New Zealand and the US were two of the 12 states who agreed terms of what was widely predicted to be the most comprehensive trans-regional Free Trade Agreement (FTA) ever established. At the time of the 2015-16 UNSC tenure, the TPP was predicted to result in substantial income growth for New Zealand by 2025, contingent on the US export market in the final agreement (Petri and Plummer 2012, 6).

Strategically, New Zealand is also now a 'partner' with the US in the Asia-Pacific region, through both the 2010 Wellington Declaration and the 2012 Washington Declaration of Closer Defence Co-operation. However, the Washington Declaration of Closer Defence Cooperation uses language carefully constructed to ensure no infringement on New Zealand's independence, at no time referencing a commitment to join the other in security action and each state agreeing to 'full respect of the independence, self-reliance and sovereignty of the other Participant' (New Zealand Government and United States of America 2012, 1). This protection of New Zealand's independence was reinforced by then-Prime Minister John Key, as he stated that both parties had 'agreed to work around'(Key 2010a, 2) the stalemate on New Zealand's anti-nuclear identity to build the strategic relationship (Key 2010a, 2).

In parallel, New Zealand's economic dependence on China has changed dramatically between the two UNSC tenures. In 1993, China was New Zealand's sixth largest export market, with less than three percent of New Zealand exports going to the country (Bowman and Conway 2013,6). A substantial shift in the economic interactions between the two countries began when New Zealand became the first Organisation for Economic Co- 
operation and Development (OECD) country to sign a FTA with China in 2008 (New Zealand Ministry of Foreign Affairs and Trade 2013, 2). China's export share has risen dramatically such that in December 2014 China was New Zealand's second largest export market with 17.4 percent of total exports, at NZ\$11.812 billion (Statistics New Zealand 2015a). China overtook the US as an export market for New Zealand in 2009 (Bowman and Conway 2013, 1), such that in 2014 the US was New Zealand's third largest export market at 10.7 percent or NZ\$7.282 billion (Statistics New Zealand 2015b).

With this substantial increase in New Zealand's strategic or economic engagements with two of the powerful UNSC P5 states, did the New Zealand public still prioritise independence as national identity content during the 2015-16 UNSC tenure? In the case of the increased strategic relations with the US, the New Zealand public remains reticent to follow the US in international actions. The resounding majority of the New Zealand public surveyed in 2017 against following the US into any military action in Syria is a very clear indication that there is still no 'blind following' of the US supported by the New Zealand public, despite political elite stating they would not rule out the action (1NEWS 2017).

The New Zealand public's prioritising of independence from China for the 2015-16 period is less clear to ascertain. As discussed earlier, a 2012 survey of the importance of foreign policy goals to the New Zealand public ranked strengthening the economy almost 30 percent ahead of all other foreign policy goals (Headley and Reitzig 2012, 78). In a 2015 New Zealand public perceptions of Asia survey, 82 percent of respondents believed it was important for New Zealand to develop cultural and economic ties with the peoples and countries of Asia (including China) (Asia New Zealand Foundation and Colmar Brunton $2016,5)$ and 80 percent believed any conflict, threat or instability in Asia could have impacts on New Zealand, including economic (Asia New Zealand Foundation and Colmar Brunton 2016, 33). This illustrates the appreciation by the New Zealand public of the importance of China to the country's economy. Chinese represented 3.9 percent of the population in New Zealand in 2013 (Statistics New Zealand n.d., 12), which implies that, should a situation arise challenging the country's independence from China, Chinese-New Zealander affiliation to China would have low impact on the general New Zealand public's prioritisation of its independence national identity content. That is, domestic political pressure on New Zealand's political elite to align with China due to Chinese-New Zealander affiliation to China would be lower than the domestic political pressure to align with the strongly 
prioritised general New Zealand identity content of being independent, as the Chinese-New Zealander proportion of the domestic voting population was a small minority. Combining the impact of the changed relationships with both the US and China, it is argued that the New Zealand public prioritisation of independence was moderate to strong for the 2015-16 UNSC tenure, with caveat that potentially independence from the US would be prioritised more strongly than independence from China by the New Zealand public during this period.

\section{Relational: What New Zealand is Not}

A review of the strongly prioritised content of both the UNSC tenures gives a clear indication of relational content that defines the New Zealand national identity by what it is not. New Zealand's low prioritisation of Western ally content in both 1993-94 and 2015-16 and low British colonial content prioritisation independence in 1993-94 combine with the prioritisation of the independence content in each period to indicate the relational content of what New Zealanders believe their national identity is not to be perceived as by the international community.

In each period, the relative prioritisation of each identified national identity content combines in a similar way to this relational content determination, providing a 'win-set' of national identity content as set out in Table 1 below. It is argued that these 'win-sets' provide the bounds of actions that New Zealand's political elite could take in international engagements during each period while still retaining domestic support. In Chapter V, these 'win-sets' form the constructivist lens for in the combined theoretical framework in analysis of New Zealand's actions on the UNSC.

\begin{tabular}{|l|c|c|}
\hline \multirow{2}{*}{ National Identity Content } & \multicolumn{2}{|c|}{ Priority Given to National Identity Content by New Zealand Public } \\
\cline { 2 - 3 } & 1993-94 UNSC Tenure & $\mathbf{2 0 1 5 - 1 6}$ UNSC Tenure \\
\hline British Colonial History & Low & Moderate \\
\hline Western Ally & Low & Low \\
\hline Bicultural & Strong & Strong \\
\hline Multicultural & - & Strong \\
\hline Pacific State & Low & Moderate to Strong \\
\hline Nuclear Free & Strong & Strong \\
\hline Principled, Good Global Citizen & Strong & Moderate to Strong \\
\hline Independent & Strong & (n) \\
\hline
\end{tabular}

Table 1. New Zealand Public Prioritisation of National Identity Content, 1993-94 and 2015-16 


\section{New Zealand's Actions on the United Nations Security Council: 1993-94 and 2015-16}

\section{The UN Security Council}

The UNSC was established at the end of WWII and was conferred by the UN member states 'the primary responsibility for the maintenance of international peace and security' (United Nations 1945 Chap 5 Article 24). The UNSC consists of fifteen member states of the UN, with the great powers that were the victors of WWII - the UK, France, Russia, the US and China - making up the P5, and the remaining 10 non-permanent seats elected on a regional basis to serve two-year terms, with a stagger of elections. All of the P5 and at least four elected non-permanent members (E10) (making a total of nine) must vote in any matter (such as UNSC resolution or statement) for it to be approved and binding on all UN member states (United Nations 1945 Chap. 5 Article 27), effectively giving the P5 the power to veto any UNSC resolution. At date of writing, the veto has been enacted 237 times in total by the P5 in UNSC voting, with the US enacting its right of veto 79 times and China 11 times (Sciboz n.d.). The Presidency of the UNSC is rotated through all member states alphabetically, with the duration of each Presidency lasting one calendar month. The UNSC President has the power to place issues on the UNSC meeting agenda, providing avenue for issues of the state's concern, or the state's interests, to be raised to the Council (Thorhallsson 2012, 156). The UNSC also establishes working groups and committees to assist the UNSC to perform its function, for example in development of sanctions programmes. These subsidiary organs to the UNSC are constituted by the sitting UNSC members, with chair and vice-chair of each determined annually by the UNSC (United Nations n.d.). For procedural matters, nine members of the UNSC must vote to approve a council action, such that the P5 do not have power of veto for UNSC procedural decisions (United Nations 1945 Chap. 5 Article 27).

As an E10 member on the UNSC, actions New Zealand could take to achieve interests or to align with national identity content encompassed drafting (essentially sponsoring) UNSC resolutions, voting to approve or reject UNSC resolutions or choosing to abstain from voting, acting as chair or vice-chair for subsidiary working groups and, during Presidency rotation, putting issues on the UNSC agenda. In addition to these proactive actions, New Zealand could make statements during sessions of the UNGA to indicate New Zealand's position on issues where UNSC resolution has not been achieved, and release statements of explanation behind the country's voting position to indicate New Zealand's position on issues. New 
Zealand was also able to initiate and chair 'Arria-Formula' meetings, which are informal briefings on themes or issues of the initiating UNSC member's concern or interest to UNSC members, who may or may not elect to attend (United Nations Security Council n.d.).

In this chapter, for both the 1993-94 and 2015-16 tenures by New Zealand on the UNSC, proactive actions taken by New Zealand to progress issues on the UNSC and/or indicated position of New Zealand on issues raised to the UNSC where either resolution was not unanimously achieved or required substantial lobbying or compromise to achieve are identified. The combined theoretical framework developed for this thesis is then applied to propose explanation of New Zealand's actions or position. For each action, the principles of the singular theories are applied in separate analysis through that theory's lens to propose single theory explanation. Under analytic eclecticism, any pragmatic connections of the singular theory analyses that provide a more comprehensive explanation for New Zealand's action in these complex substantive global issues are identified. Analytic eclecticism also allows any action taken that does not align with actions predicted for the issue under one or more theories to be identified. Context of the substantive global issue for which these instances of nonalignment arise are identified and discussed.

\section{New Zealand on the UNSC, 1993-94}

\section{UNSC Reform - Improving Peacekeeping Operations}

\section{Consultation.}

New Zealand led an initiative to allow troop contributor states in peacekeeping operations (PKOs) to have more input in UNSC decisions on the operations. New Zealand put the first proposal to the council in 1993 then worked with Argentina to draft and circulate a draft UNSC resolution to incorporate the proposed changes. The draft resolution had strong support from the other E10 members but also strong resistance from some of the P5 (New Zealand Ministry of Foreign Affairs and Trade 1995, 10-11; Templeton (ed.) 1995 Part 3). It is not documented which of the P5 was opposed. New Zealand diplomats speculated the P5 opposition as either a desire to retain the opaque status quo (Templeton (ed.) 1995 Part 3) or, more diplomatically, due to potential conflict with role of the UN Secretariat (New Zealand Ministry of Foreign Affairs and Trade 1995, 11). Compromise was achieved (New Zealand Ministry of Foreign Affairs and Trade 1995, 11) and a statement by the President of the UNSC was released in November 1994 setting out that meetings 'should be held as a matter of course'(United Nations Security Council 1994) between the UNSC, troop contributor and 
the UN Secretariat for decisions on PKOs, to be joint chaired by the UNSC and UN Secretariat (United Nations Security Council 1994, 62).

Consultation for PKOs was successful achievement of part of a 'sustained New Zealand initiative' (New Zealand Ministry of Foreign Affairs and Trade 1995, 10) to improve the management of PKOs and ensure UNSC decision-making transparency (New Zealand Ministry of Foreign Affairs and Trade 1995, 10). It is not known which of the P5 opposed New Zealand's initiative, however all P5 are large powers with significant military and economic capability. In continuing to pursue an initiative clearly not the interests of the P5, aligning itself only with a medium power (Argentina), New Zealand's action can neither be explained as bandwagoning nor balancing through the neo-realist lens. With the UK being New Zealand's third largest export market in 1994 and the US its fourth (Bowman and Conway 2013, 2), New Zealand's action cannot be explained as in pursuit of the state's material (economic) interests through the commercial neo-liberalist lens. Increased trust in the UNSC by all UN member states as a fair and honest international body would be achieved through greater transparency, and so New Zealand's pursuit of strengthening the UNSC as the prime authority to maintain international peace and security can be explained under the institutional neo-liberalist lens, as it would provide greater protection to small states like New Zealand by increasing the international acceptance of the norms and rules the UNSC establishes. New Zealand was also representing the interests of small states who were the majority troop contributors to the PKOs of the time (O'Brien, McIntosh (ed.), and McKinnon (ed.) 2007, 67). With content of being a principled, good global citizen strongly prioritised, and British history and Western ally content low while independence content was strongly prioritised, the actions taken by New Zealand's political elite are as also in line with popularly internalised New Zealand national identity through the constructivist lens.

Convention on the Safety of UN Personnel

New Zealand used its first rotation as President in March 1993 to raise concern at the increased casualties to UN peace keepers. New Zealand proposed a new international legal instrument to improve the safety of UN and humanitarian aid personnel, with the key tenet of any person responsible for attacking UN and associated personnel could be held accountable under international law no matter where they were found (New Zealand Ministry of Foreign Affairs and Trade 1995, 39-40; O’Brien, McIntosh (ed.), and McKinnon (ed.) 2007, 67). This proposal was endorsed by the UNSC through resolution in September 1993 (United 
Nations Security Council 1993) and an Ad Hoc UNSC committee subsequently developed the intent of New Zealand's proposal into the Convention on the Safety of UN Personnel, which was adopted by UNGA vote in December 1994 (United Nations n.d.).

New Zealand's drive behind this proactive action to establish international law providing greater safety for UN peacekeepers can be seen in part as means to improve the safety of its own citizens deployed on PKOs. The number of NZDF personnel deployed on UN PKOs in 1994 rose to 327, across nine different operations, compared with only 50 in 1991 (New Zealand Ministry of Foreign Affairs and Trade 1995, 30), meaning there was now a five fold increase in New Zealand citizens at risk. Such action to protect citizens can be explained as self preservation of the state under neo-realism and can also be explained through institutional neo-liberalism, as the establishment of international law further strengthened the trust in the UNSC by the smaller, developing states who were the majority troop contributors, validated its standing as the international authority for peace and stability. Advocating for the concerns of the small, developing states is also aligned with the strongly prioritised national identity content of being a principled, good global citizen, and so the constructivist lens rounds out a full explanation for this action across the all theoretical elements of the analytical framework of this thesis.

\section{Iraq Sanctions Committee}

New Zealand chaired the Iraq Sanctions committee for the duration of its two year UNSC tenure. While the sanctions committee was 'dominated by permanent UNSC members (in particular the US, UK and France) (O’Brien, McIntosh (ed.), and McKinnon (ed.) 2007, 62), New Zealand used its position to ensure a consistent approach was taken to applications for imports and exports to Iraq was taken (New Zealand Ministry of Foreign Affairs and Trade 1995, 36), believing it was needlessly stringent and 'from a chair's perspective, often illogical' (O’Brien, McIntosh (ed.), and McKinnon (ed.) 2007, 62). During New Zealand's chair tenure, processing of applications to the committee reduced from three months to three to four weeks, with the number of applications increasing from 1500 to 6500 per year, with New Zealand political elite claiming this provided 'enormous practical benefit to the people of Iraq' (New Zealand Ministry of Foreign Affairs and Trade 1995 Part 3).

Working to improve practical aid to the people of Iraq against pressure from traditional Western allies and major trading partners cannot be explained through the neo-realist lens. The institutional neo-liberal lens can be used to explain motivation to improve the efficiency, 
and so trust, in a multilateral institution through the practical logistical improvements achieved in New Zealand's chair tenure, even though the commercial neo-liberal lens would expect New Zealand to align with the interests of its significant trading partners, the US and UK. The constructivist lens adds explanatory power in combination with neo-liberalism, as the action aligns with the strongly prioritised national identity content of being a good global citizen, practically aiding the people of Iraq, while low prioritisation of British historical ties and Western alliance content ensures other national identity characteristics were not contradicted by the action.

\section{Somalia}

Under New Zealand's Presidency in March 1993, the UNSC agreed a mandate for peace enforcement and humanitarian operations in Somalia (UNOSOM) where, for the first time, the US agreed for its troops to be under UN command. However, the US established its own parallel command chain and the resultant confused command and control is blamed for substantial US casualties in Mogadishu in 1993 (O’Brien, McIntosh (ed.), and McKinnon (ed.) 2007, 62). The US became increasingly insistent on swiftly closing down UNOSOM , under significant domestic pressure to remove the US from UN command (Smith 2014), and the UNSC was split over mission end date (New Zealand Ministry of Foreign Affairs and Trade 1995, 20). New Zealand led a UNSC mission to Somalia in 1994 to reinforce its case for a staged withdrawal to ensure UN humanitarian assistance would still be available. New Zealand's leadership led to UNSC consensus of a withdrawal date for UNOSOM of March 1995, allowing the UN to achieve humanitarian aid objectives (New Zealand Ministry of Foreign Affairs and Trade 1995, 20).

New Zealand took a lead position on UNOSOM in direct counter to the interests of the US, and likely other members of the P5. With no state material interests in the region, New Zealand's actions cannot be explained through the neo-realist lens. Institutional neoliberalism can provide explanation in New Zealand not wanting the UNOSOM mission to be seen by the international community as a failure, as this would degrade the strength of the multilateral institution and the rules and norms it offered to secure New Zealand's interests as a small state. Combining to provide greater explanatory power is the constructivist lens interpretation that the action taken aligns with New Zealand's strongly internalised national identity content of being a good, principled global citizen. With human rights abuses increasing through 1994 (Human Rights Watch n.d.), the constructivist lens explains New 
Zealand's political elite actions through the national identity content where, as a good global citizen, it acted to ensure the international community did not abandon the people of Somalia. New Zealand's strongly prioritized independence national identity content provided avenue for it to stand up against the US for what its national defining values determined was morally right.

\section{Bosnia - Arms Embargo}

New Zealand abstained from voting for a US-sponsored UNSC resolution in November 1994 to lift the arms embargo sanctions on Bosnia and Herzegovina, at a time when the fledgling Muslim nation was under increasing attacks and human rights abuses by Serbia and sought to defend itself. The resolution received only six votes in favour, with all other members abstaining including New Zealand and the remaining four of the P5 (Meisler 1993). In New Zealand's explanation of its vote, it reiterated its condemnation of the 'repugnant concepts of ethnic purity' (New Zealand Ministry of Foreign Affairs and Trade 1995, 27) of the Bosnian Serbs while stating it could not support lifting of the arms embargo as 'to take such a step would be to move away from collective action' (New Zealand Ministry of Foreign Affairs and Trade 1995, 27).

While this stated drive behind New Zealand's position can again be explained through institutional neo-liberalism, as a small state seeking to ensure the norms and rules of multilateral institutions are followed by all states to ensure its own security, addition of the constructivist lens enhances explanatory power. Ethnic cleansing by the Serbs invokes the strongly prioritised bicultural and principled, good global citizen national identity content, to both ensure all ethnicities are treated fairly and equally and protection of human rights. However, the support for resolution of conflict by increasing arms to one side, or promoting military conflict, can be seen to go against the defining morals of the national identity content of being a global peacekeeper.

\section{Georgia}

New Zealand expressed concern at the deployment of Russian troops as part of a regional peacekeeping force to operate in cooperation with a UN observer group under the UNSC sanctioned UN Mission in Georgia. New Zealand voted to support the unanimously approved resolution authorising the major Russian troop contribution, but expressed its concern in formal explanation of vote, stating that the country 'does not believe it is a good precedent for a neighbouring state to play such a predominant role in such a force' and 
voiced concerns that Russian forces would not operate transparently under the UN PKO framework (New Zealand Ministry of Foreign Affairs and Trade 1995, 15-16). While this was a voiced position by New Zealand, not demonstrated by proactive action in form of its vote on the resolution, New Zealand did express its distrust of a major power and member of the P5, Russia. This action cannot be explained under neo-realism, as all other UNSC members voted in support of the resolution with Russia and so New Zealand was neither bandwagoning nor balancing in the anarchic international system and New Zealand had no material interests in the region. New Zealand's position reinforced its call for all states, regardless of capabilities or relative regional power, to adhere to the international norms established by the UNSC, and so can be explained through the institutional neo-liberalist lens as the state's pursuit for international respect of multilateral institutions. New Zealand's concern of ulterior motivations by Russia, as a state with history of pursuit of material interests in Georgia, can also be explained through the constructivist lens as New Zealand's political elite taking action aligning with the national identity content of being a principled, good global citizen.

\section{Haiti}

In 1994 the US and Argentina sponsored a UNSC resolution authorising the US to take military intervention to restore legitimate government in Haiti (New Zealand Ministry of Foreign Affairs and Trade 1995, 16). New Zealand was concerned that the major regional power (US) would be authorised to intervene under the banner of the UN and believed that strict accountability was required on the use of force. With Spain, New Zealand initiated several days of debate in the Council which resulted in changes to the draft resolution to improve accountability and ensure oversight by UN monitors (New Zealand Ministry of Foreign Affairs and Trade 1995 Part 3). New Zealand subsequently provided four monitors to the mission in Haiti, supporting its position for accountability and reporting (New Zealand Ministry of Foreign Affairs and Trade 1995, 16).

New Zealand's challenge to the intent of the US to operate in the name of the UN in Haiti but without full accountability cannot be explained through the neo-realist lens, as collaboration with Spain cannot be seen as balancing against the capabilities of the global hegemon and New Zealand had no material interests to be gained by intervening in the region. With the US export market important to New Zealand economically, taking a stand against the major power cannot be explained as in pursuit of the state's economic interests under commercial neo-liberalism. However, reinforcing that the same rules apply to the US as all other states 
contributing to UN PKOs can be explained by institutional neo-liberalism, as New Zealand strove to ensure all states adhered to the norms and rules of the UNSC as an authoritative multilateral institution. Constructivism offers further explanatory power for the position taken by New Zealand; with independence strongly prioritised and Western ally content low in priority, New Zealand's political elite were enabled to take a stand against the US in line with its other strongly prioritised national identity content of being a good global citizen. Employing analytic eclecticism, national defining values of fairness and equality motivating the actions of New Zealand's political elite in combination with the drive to pursue state interests of reinforcing the authority of multilateral institutions over all states provides strong combined theoretical explanation through constructivism and neo-liberalism.

\section{Rwanda}

On 6 April 1994, with New Zealand holding Presidency, the UNSC was informed of increasing ethnic conflict in Rwanda, where a UN assistance mission (UNAMIR) was at operating under UNSC mandate to monitor the ethnic conflict ceasefire agreement. On 7 April, the UNSC was informed that the ceasefire was over, ten UN peacekeepers had been murdered and the UNAMIR force was in immediate danger as ethnic violence raged in the Rwandan capital of Kigali, with both politicians key to the peace process and civilians being killed (Barnett 2002, 97-99). What occurred in the UNSC over the weeks that followed has been widely acknowledged as a grave failing of the Council as Rwandan Hutus carried out calculated ethnic cleansing of Tutsis (Conley Tyler and Pahlow 2014, 98; Brunk 2008, 25). Before the April violence, the UNSC had been divided into two camps; those wanting to authorise UNAMIR to intervene in the deteriorating situation in Kigali to protect civilians, led by New Zealand with Nigeria and the Czech Republic, and those wanting to withdraw the UNAMIR and close the mission, led by the US and Britain with France, Russia and China in support - the full P5. The US' position was driven by domestic pressure to show that it could be tough on failing UN operations, following the US losses in Somalia in 1993 (Barnett 2002, 100-101). As more information on the atrocities in Kigali were brought to light through media and NGOs, although not transmitted by the Secretariat from clear communication of the situation by UNAMIR, New Zealand stood against the P5 as it insisted that the UNSC acknowledge the violence as genocide and militarily intervene. New Zealand created a coalition with other E10 members to force the UNSC into action, and were eventually successful in gaining support from Britain and China. In the last days of its Presidency, New Zealand drafted a resolution using the word 'genocide' and a mandate for protection of 
genocide victims. Although a debate could not result in an approved UN resolution, New Zealand's steadfastness did succeed in the release of a statement condemning the action. Although the statement did not achieve New Zealand's aim of declaring the Rwandan massacre a 'genocide', the UNSC release provided avenue for a neutral UN force to protect the victims (Conley Tyler and Pahlow 2014, 97-98). The Rwandan genocide remains a badge of shame on the UNSC for its impotence and non-intervention however, New Zealand was acknowledged for 'being on the right side of history' (McLay 2011, 126), and praised for its leadership and willingness to stand in the face of P5 opposition (Conley Tyler and Pahlow 2014, 97).

The actions of New Zealand in this leadership cannot be explained through neo-realism, with no material interests to be gained in standing against the full P5, two of whom were major trading partners. Institutional neo-liberalism provides explanation of drive to pursue the state's interests by ensuring the UNSC was seen to act on the substantial concern in the global community of the violence in Rwanda, to retain support as the global authority for maintenance of peace and stability. However, it is the constructivist lens that provides the most explanatory power for New Zealand's dogged determination to force the UNSC into action. Its strongly prioritised national identity content of independence, and low priority of Western ally and British history, enabled New Zealand's political elite to act in line with the strongly prioritised national identity content of biculturalism, which invoked even more strongly the content of being a principled, good global citizen in reaction to the atrocities of ethnic cleansing. Had New Zealand's political elite not taken the strong position that they did in attempt to protect the victims of ethnic cleansing, it is argued that the New Zealand public would have reacted negatively at actions that were against the strong collective identity they held as differentiating the country in the international system.

\section{New Zealand on the UNSC, 2015-16}

\section{Iran Nuclear Programme Agreement}

In July 2015, during New Zealand's Presidency of the UNSC, the Council unanimously adopted Resolution 2231, endorsing the Joint Comprehensive Plan of Action (JCPOA) on Iran's nuclear programme, signed in Vienna by the P5 plus Germany, the European Union and Iran. As President of the UNSC, the New Zealand Foreign Affairs Minister, Murray McCully, expressed New Zealand's belief that the JCPOA 'represented a triumph of 
diplomacy and cooperation over confrontation and mistrust' (United Nations Security Council 2015), and to implore that 'this should guide the Council in tackling the extraordinarily difficult challenges in the Middle East — in Syria, Iraq, Yemen and Libya' (United Nations Security Council 2015).

The agreement of the JCPOA, and its subsequent UNSC endorsement, has been analysed as a success for 'idealist multilateralism' (Jeffries 2015), and New Zealand's motivation to support the JCPOA can readily be explained through the institutional neo-liberalist lens of this analytical framework, as strengthening the international adherence to norms and rules of multilateral institutions protects New Zealand's sovereignty as a small state. Equally, the explicit statement by New Zealand's political elite that this agreement should be modelled to resolve other contentious international conflicts can be explained as drive to ensure adherence to multilaterally agreed norms and rules to establish peace and stability. Employing analytic eclecticism by adding the constructivist lens of national identity provides further explanatory power for New Zealand's strongly expressed support of this agreement. Although the JCPOA does not preclude the eventual ability for Iran to develop nuclear weapons, seemingly in contradiction to New Zealand's moderately prioritised national identity content of being nuclear-free, the bounds on Iran that will delay any weapons development and allow the international community visibility to Iran's nuclear capabilities for 15 years (Gordon and Sanger 2015) are in line with the nuclear non-proliferation element of the New Zealand nuclear free identity content. Had the nuclear free national identity content have been more strongly prioritised, it is proposed that the New Zealand Foreign Minister may have been compelled to add caveat to his lauding of the agreement to warn Iran against eventual development of nuclear weapons.

\section{Small Island Developing States}

New Zealand used the opportunity of its Presidency in July 2015 to raise the threats to peace and stability of small island developing states (SIDS) to the attention of the UNSC. New Zealand sponsored and chaired debate on SIDS' concerns, and in advance produced documentation to guide UNSC members on the prime threats to peace and stability of SIDS, including climate change and transnational crime (United Nations 2015). New Zealand invited representatives from SIDS across the globe to brief and join the debate. Over 70 states were represented, including a large proportion of Pacific states. The debate was the first time that the collective issues of SIDS have been brought to the direct attention of the UNSC (New Zealand Herald 2015). Acting as President of the UNSC, the New Zealand 
Foreign Minister stated that New Zealand 'viewed its own peace and security as being directly affected by the prosperity and stability of the small island developing states in its region, the Pacific' (United Nations 2015).

The expression by New Zealand's political elite of the connection between the stability of Pacific SIDS and country's own security supports explanation of New Zealand's proactive sponsorship of the SIDS debate as in line with its material interests through a neo-realist lens. However, the degree that New Zealand's interests would be threatened by instability in Pacific SIDS is arguably not substantial enough for neo-realism to hold convincing explanatory power for the degree of effort expended by New Zealand. As SIDS do not make up a significant export market for New Zealand, commercial neo-liberalism does not offer an explanation for New Zealand's strong advocacy for the concerns of SIDS. Greatest explanatory power for New Zealand's proactivity to give SIDS, including Pacific states, an audience with the UNSC can be provided through employing analytic eclecticism by combining the institutional neo-liberalist lens and the constructivist lens of national identity. Ensuring that SIDS regard the UNSC as an accessible authority for global threats to their peace and stability explains New Zealand' action as pursuing the state's interests by ensuring multilateral institutions, and the international norms and rules they propagate, are respected by all states, regardless of size. The moderate to strongly prioritised national identity content of New Zealand as a Pacific state and strongly prioritised content of being a principled, good global citizen explain the New Zealand political elites drive to advocate for their neighbours in the Pacific and for small states whose issues would not otherwise be raised to the UNSC. New Zealand's national identity defining moral values of fairness and equality explain New Zealand's drive to ensure less powerful states have the opportunity to be heard at 'the high table of international relations' (McLay 2011, 5). Ensuring that global concerns of climate change and transnational crime are raised to the UNSC further aligns with New Zealand acting as a good global citizen. The SIDS are effected by these issues of global concern to a far greater degree than the larger states on the UNSC, many of whom hold the power to make a difference in combating these threats for all states (New Zealand Herald 2015).

\section{Human Rights Issues for UN PKOs}

In March 2016, New Zealand co-initiated and co-chaired with Uruguay an Arria-Formula meeting on Human Rights issues for UN PKOs, allowing the heads of the human rights components of UN missions in Darfur, Congo, Iraq, Mali and the Central African Republic to 
brief UNSC members (Daws and Sievers 2017, 12; What's In Blue 2016). The ArriaFormula meeting provided an opportunity for an informal exchange on human rights work on the ground on UN missions, allowing UNSC members to better understand how human rights components contribute to the success of the overall UN peace operations, and also providing opportunity to improve UNSC mandates to better enable the success of human rights components (What's In Blue 2016).

Neither neo-realism nor commercial neo-liberalism provide explanation of New Zealand's proactive initiation of a briefing session to improve human rights components on UN PKOs, particularly where those missions represented at the briefing were mainly located in Africa, far removed from threats to New Zealand's sovereign security and economic interests. Through the institutional neo-liberalist lens, New Zealand's advocacy of the briefing session can be explained as steps to ensure effective UN missions that in turn retain international respect for the UNSC as the international authority to maintain peace and stability, pursuing the small state's interests. Addition of the constructivist lens through analytic eclecticism provides enhanced explanatory power, with New Zealand's strongly prioritised national identity content of being a principled, good global citizen driving its political elites' advocacy for human rights components to be improved on UN missions, and push for those working at the 'coal face' of human rights on behalf of the UN to have a rare audience with the UNSC to ensure their issues are heard. This is arguably most relevant for those UN missions in Africa, where global response to conflicts and human rights abuses have in the past been criticized as politically indifferent (Wiharta 2010).

\section{Syria}

As President in September 2016 New Zealand initiated debate on the crisis in Syria, despite reports that other UNSC member states 'counselled against it' (Watkins 2016a). In advance of the UNSC debate, New Zealand Prime Minister John Key addressed the UNGA, blaming internal politics of the UNSC as well as the complexity of the conflict for lack action by the Council, while also condemning 'the vested interests' (Watkins 2016a) of UNSC members for preventing agreement on action to prevent the conflict from 'spiralling out of control' (Watkins 2016b). Opening the UNSC debate as President, Key stated New Zealand was raising the debate on Syria as 'no other issue more urgently demands the attention of world leaders' (Key 2016) and called out the ineffectiveness of the UNSC by naming the ongoing humanitarian crisis in Syria as a result of "collective political failure, including by this Council, to do what must be done to end the conflict' (Key 2016). Key stressed that the 
conflict cannot be ended by Syrians alone and stated that UNSC Resolution 2554 approved in December 2015 set out the pathway to end conflict but was not implemented, naming the US, Russia, Iran, Saudi Arabia and Turkey as 'those countries with greatest ability to influence events [that] have a particular responsibility in this regard' (Key 2016). Despite New Zealand's initiative, no resolution was reached on Syria during its final tenure as UNSC President. In October 2016, France proposed a draft resolution on Syria, co-sponsored by the US and Britain of the P5 and 43 other UNGA member states, that required cessation of aerial bombardments and all military flights over the city of Aleppo (United Nations Security Council 2016a), which was vetoed by Russia (Sciboz n.d.). Russia subsequently proposed a new text with reference to airstrikes and flights removed, which was rejected by the UNSC (Nichols 2016). On 5 December 2016, during its final month on the UNSC, New Zealand cosponsored with Egypt and Spain a draft resolution on Syria demanding an end to all attacks, including airstrikes, in Aleppo and other requirements to ensure safe provision of humanitarian aid and steps to conflict resolution talks (United Nations Security Council 2016b). Both Russia and China vetoed the New Zealand drafted resolution (Sciboz n.d.). New Zealand's motivation to sponsor the resolution on Syria was provided by its Ambassador to the UN, Gerard van Bohemen:

\footnotetext{
"The council has a responsibility to try to address what is clearly the biggest issue on its agenda and with the level of killing and destruction that is going on just to give up seems to us not to be an acceptable course of action" (Nichols 2016).
}

New Zealand's actions to push strongly for a resolution ending air strikes in Aleppo cannot be explained under commercial neo-liberalism, as acting prominently in a manner that is not in the interests of China cannot be aligned with pursuit of the state's economic interests, with China being New Zealand's second largest export market. Indeed, New Zealand's actions seem to be in contradiction to those that would ensure continued good trade relations with China; leadership of a resolution that China felt strongly enough against to veto rather than simply abstain from voting on. China's motivations for its veto for this resolution have not been publicly documented, but can be construed (from later similar veto on Syria resolutions again calling for an end to airstrikes and condemning the use of chemical weapons (Reuters 2017)) to be due to an alignment with Russia that somehow achieves China's interests. 
The constructivist lens provides explanation for New Zealand's overt efforts to achieve a UNSC resolution for action by the international community to end the Syrian conflict. Despite resounding calls by the international community for UN-sanctioned intervention to resolve the world's greatest humanitarian crisis since World War II (Witte 2015), and with reports of more than 470,000 civilians killed by February 2016 and 4.8 million refugees outside Syria in March 2016 (Human Rights Watch 2017), the determined drive of New Zealand's political elite to achieve consensus on a UNSC mandate authorising international action to attempt to end the conflict aligns with the strongly prioritised national identity content of being a principled, good global citizen. The human cost of the conflict arguably invoked New Zealand's defining moral values and support for human rights for the New Zealand team, as well as the content constitutive element of New Zealand being a global peacekeeper. That the UNSC have failed to agree due to vested interests, widely acknowledged as opposing strategic interests of Russia and the US (Pillar n.d.), can be argued to invoke the moderate to strongly prioritised national identity content of independence to support the principled drive for New Zealand to take action. This independence national identity content, combined as a 'win-set' with low priority of Western ally content, enables the strength of statement from New Zealand's political elite of New Zealand's condemnation of the P5, despite substantial economic dependence on one (China), and potential for increased economic interests (under the TPP, still agreed by the US at the time) and a renewed strategic relationship with another (US).

\section{Israel/Palestine}

New Zealand co-sponsored a resolution condemning continued Israeli settlement building in occupied Palestinian land in December 2016. Initially co-sponsored with Egypt, US President-elect Trump's administration applied pressure and Egypt removed its support, leaving New Zealand as co-sponsor with Malaysia, Senegal and Venezuela. The US, under the administration of outgoing-President Obama, abstained from voting and all 14 other UNSC members approved the resolution (A. Young 2017). In the immediate aftermath, Israel recalled its Ambassador from New Zealand and the Israeli Prime Minister was quoted warning New Zealand's Foreign Minister that New Zealand's continued sponsorship of the resolution would be considered by Israel as 'a declaration of war' (New Zealand Herald 2016b).

In advance of New Zealand co-sponsoring the resolution, New Zealand Foreign Minister Murray McCully met with US Secretary of State John Kerry to discuss the Israel-Palestine 
conflict. New Zealand expressed its preference for the US and Middle Eastern states to take the lead in initiating a new resolution, but stated that New Zealand would step up if necessary to see a resolution put to the Council, as making progress on the conflict was one of New Zealand's primary aims for its tenure on the UNSC. McCully stated that discussions with the outgoing US Obama-administration had included agreement that a two state solution to the conflict was being threatened by continued Israeli settlement building in occupied Palestinian land in the West Bank, along with New Zealand's determination that a UNSC restatement of the principles of the two state solution was necessary (A. Young 2016b).

New Zealand's action in leading this Israel-Palestine resolution can be explained through institutional neo-liberalism, as the country strives to ensure that rules set by the UNSC for international conflict resolution are respected by all states, protecting its status as the authority for maintaining international peace and security. However, through the lens of neorealism, the continued leadership on this resolution by New Zealand appears to counter the preservation of its strategic relationship with the US under the incoming Trump administration (despite an abstention from the US under the Obama administration effectively giving New Zealand its 'blessing' to proceed with the resolution). While verbal threats of war by Israel also support that New Zealand's actions directly opposed its self preservation under neo-realism, New Zealand's geographic isolation reduced the threat to its security that Israel could realistically pose.

The constructivist lens provides explanation for New Zealand's actions so strongly countering pursuit of the state's interests under neo-realism. New Zealand's strongly prioritised national identity content of being a principled, good global citizen enables New Zealand's political elite to take international actions that ensure fairness and equality. By building on occupied Palestinian land, Israel threatens the possibility of the conflict being resolved by the declaration of two independent states. A single state solution to the conflict would result in 'two different standards for citizenship' (A. Young 2016b), with high potential for mistreatment of Palestinians by an Israeli majority (A. Young 2016b). New Zealand's strongly prioritised bicultural and multicultural national identity content provide strong drive to ensure equal treatment and rights for all peoples of all ethnicities, combining with the principled, good global citizen content to provide a driving 'win-set' for New Zealand political elite to strive for a resolution that ensures fairness and equality. 


\section{A Comparison of Two UNSC Tenures}

In the era of globalisation spanning the two periods of New Zealand's most recent UNSC tenures, New Zealand governments have consistently proclaimed the country's commitment to multilateralism (New Zealand Ministry of Foreign Affairs and Trade n.d.; Patman 2005, 13). The UN stands as the prime multilateral body for the maintenance of rules-based international order, with the UNSC the prime authority for maintaining international peace and security. The analysis of this chapter shows that New Zealand's actions during both its 1993-94 and 2015-16 UNSC tenures have consistently aligned with the institutional neoliberalist aim of reinforcing the authority of the UNSC in the international system, be it through improved efficiency, enabling accessibility for all states or ensuring transparency. With protection of New Zealand's security and interests as a small state in an anarchic international system provided by all states acting within the norms and rules agreed in multilateral institutions, New Zealand was prepared to take proactive actions during both the 1993-94 and 2015-16 UNSC tenures that neither advanced pursuit of its material interests through the neo-realist lens, nor its economic interests as explained through the commercial neo-liberal lens, in order to reinforce the international authority of the UNSC. This was demonstrated, among other actions, by its leadership of the Iraq Sanctions committee through 1993-94 and by its advocacy to ensure the concerns of SIDS were heard by the UNSC in 2015-16.

However, there are actions by New Zealand during both tenures analysed in this chapter as directly counter to pursuit of its material interests and that cannot be explained through institutional neo-liberalist reinforcement of rules-based world order. In 1993-94, the strong stand against the P5 over the lack of action by the UNSC during the Rwandan genocide and in 2015-16 the same strength of condemnation against powerful states in the P5 over the inability of the Council to agree authorisation of international intervention in the humanitarian crisis caused by the Syrian conflict. Equally, New Zealand's actions to secure a resolution on the Israel-Palestine conflict in 2015-16 in the face of clear opposition of the incoming US administration and Israel and, in 1993-94, to stand against the US both to ensure appropriate UN withdrawal date from Somalia and accountability of US forces in Haiti, were counter pursuit of New Zealand's economic interests, even while securing international regard for UNSC authority. Through employment of analytic eclecticism, analysis of these actions through a combined theoretical framework demonstrated the power of national identity under the constructivist lens to expand on traditional IR theories to 
explain New Zealand's actions in the international system. The national identity content 'win-sets' established in this thesis show that the actions taken by New Zealand were aligned with the collective identity that was popularly internalised by the New Zealand public during each tenure. This explains why even actions that countered pursuit of New Zealand's economic interests in the 2015-16 tenure, when only a few years earlier the New Zealand public prioritised pursuit of New Zealand's economic interests over all other foreign policy goals, could be taken if it aligned with the strongest 'win-set' of national identity; being a principled, good global citizen to ensure fairness and equality for all ethnicities in an international conflict. Increased economic dependence on China and improved strategic engagement with the US have not altered the ability for the New Zealand political elite to stand against the powerful states of the P5 to act in line with the strongest prioritised national identity content of their constituents.

The analysis of this chapter illustrates the strongest benefit of employing analytic eclecticism to New Zealand's actions in the complex era of globalisation, by illustrating the conditions where New Zealand's actions on the UNSC countered pursuit of the state's material interests under traditional IR theories; that is the context of substantive global issues that invoke the strongest 'win-set' of national identity content under a constructivist lens. As such, through analytic eclecticism, the analysis of this chapter allows a key question raised in the opening of this thesis to be answered - how was New Zealand able to successfully campaign for both the 1993-94 and 2015-16 UNSC tenures under the key pillar of independence, when its international relationships had altered substantially over the intervening 21 years? New Zealand's actions during its 2015-16 tenure demonstrate that, although national identity content of independence was less strongly prioritised by the New Zealand public in comparison to during the 1993-94 tenure, a 'win-set' of national identity content existed that enabled New Zealand's political elite to take actions that were not aligned with the interests of the US and/or China. The 'win-set' of the strongly prioritised national identity content of being a principled, good global citizen, strengthened by strongly prioritised bicultural and multicultural content for key issues like Syria and Israel-Palestine and combined with low prioritisation of Western ally content, negated the effect of reduced prioritisation of independence national identity content (relative to 1993-94) when New Zealand took action on issues that needed a strong advocate for global concern. 


\section{Conclusion}

New Zealand secured its seat on the UNSC in both 1993-94 and 2015-16 by campaigning to bring an independent voice to the prime international body for maintenance of peace and stability. The substantial changes in New Zealand's economic and strategic relationships with two of the powerful states making up the P5 of the Council, China and the US, over the last decade have caused commentators to question whether New Zealand can still act independently in international engagements (TVNZ 2017).

This thesis provided analysis of New Zealand's actions on the UNSC in both tenures under the concept of analytic eclecticism. Under this IR research approach, a combined theoretical framework of traditional IR and constructivism was employed to demonstrate that New Zealand's actions can be explained as either; in pursuit of the state's material interests (in most instances to strengthen international adherence to multilateral norms and rules) and also aligned with national identity content, or; as only aligned with national identity content and counter to the pursuit of the state's material interests. With national identity argued as residing in public opinion, 'win-sets' of national identity content and the degree to which the New Zealand public prioritised these were defined for each UNSC tenure period through review of public opinion survey, allowing constructivist analysis to be conducted against the popularly internalised New Zealand national identity of the time. Employment of analytic eclecticism allowed the pragmatic connection of analyses conducted under the principles of the separate single theories to be combined to provide enhanced explanation of $\mathrm{New}$ Zealand's actions in complex substantive issues raised on the UNSC during both tenures. A key benefit of employing analytic eclecticism was realised in the analysis of this thesis; the identification of instances when New Zealand's actions were counter to the pursuit of the state's material interests under traditional IR theories. Identification of these instances then enabled identification of the substantive context of the issues that invoked the strongest 'winset' of national identity content under constructivism in order for New Zealand's political elite to take action not aligned with pursuit of the state's interests under the traditional IR theories.

This thesis argues that, due to the enablement of the unique New Zealand national identity, New Zealand's political elite were able to take actions that did not align with those of more powerful states despite impact on the state's material interests, and still retain domestic support. This was most clearly demonstrated during the 1993-94 tenure by New Zealand's 
stand against the full P5 to drive a resolution on the Rwandan genocide. During its 2015-16 tenure, the analysis of this thesis demonstrated that New Zealand was enabled to act independently of powerful states on which its material interests depend; the US and China. This was seen in the drive of New Zealand's political elite for the UNSC to agree a resolution on the Syrian conflict, against China and Russia, and in the country's sponsorship of a resolution in the Israel-Palestine conflict, against the incoming-US President Trump administration and Israel. The context of each of these substantive issues was found to invoke the strongest 'win-set' of national identity content for the relevant UNSC tenure period.

While this thesis identified change to the strength of prioritisation of some content of the New Zealand national identity between the two UNSC tenure periods, the combination of content prioritisation in the national identity 'win-sets' during each tenure was demonstrated to enable New Zealand's political elite to take independent actions on the UNSC in 2015-16, as it did during the 1993-94 tenure. The actions of New Zealand on the UNSC over 2015-16 have reinforced the ongoing social construction of the internationally regarded New Zealand national identity, which was strongly established by New Zealand's actions during its 199394 tenure; that New Zealand is a strong, independent advocate for the international good.

This thesis has demonstrated the explanatory power that is provided by combining traditional neo-realist and neo-liberal IR theories with constructivism in an analytical framework under analytic eclecticism for New Zealand's international actions. However, this research could be further supported by analysis of New Zealand's international actions using a combined analytical framework under analytic eclecticism, including the constructivist lens of national identity, for actions outside of the UNSC, including other multilateral forums and in bilateral engagements.

This thesis has contributed to New Zealand foreign policy IR scholarship in both its expansion of the analysis of New Zealand's international actions through the lens of national identity and benchmarking of New Zealand national identity content definition, as relevant to international interactions. This allows comparative analysis of national identity explanatory power at different time periods through assessment of contestation, or degree of prioritisation, by the New Zealand public. In addition, as a contemporarily relevant original contribution to New Zealand foreign policy IR scholarship, this thesis demonstrates the expanded explanatory power of a combined analytical framework employed under analytic 
eclecticism in analysis of New Zealand's actions in the contemporary era of the country's complex international relationships and globalisation. By allowing both traditional IR theories and constructivism to be employed in analysis of New Zealand's actions on the UNSC, and making pragmatic connection of analyses on complex substantive issues, the analytic eclecticism approach enabled explanation of actions that hold practical interest for both IR scholars and for New Zealand political practitioners. For New Zealand foreign policy IR scholarship, this thesis provides a step towards achieving Joseph Nye's aims to narrow the disparity between theoretical explanation and real world political action in the contemporary era. 


\section{Bibliography}

1NEWS. 2017. "Kiwis Overwhelmingly against NZ Being Dragged into Syria Conflict as English Says He 'Wouldn't Rule It out'.” 1 NEWS NOW. April 10, 2017.

https://www.tvnz.co.nz/one-news/new-zealand/kiwis-overwhelmingly-against-nzbeing-dragged-into-syria-conflict-english-says-he-wouldnt-rule.

Abdelal, Rawi, Yoshiko M. Herrera, Alastair Iain Johnston, and Rose McDermott. 2006. "Identity as a Variable." Perspectives on Politics 4 (4): 695-711.

Alley, Roderic. 1984. "The Alternatives to ANZUS: A Commentary." In Alternatives to ANZUS. Auckland: New Zealand Foundation for Peace Studies.

Alley, Roderic Martin. 2007. New Zealand in World Affairs. Victoria University Press.

Asia New Zealand Foundation, and Colmar Brunton. 2015. "New Zealanders' Perceptions of Asia and Asian Peoples - 2014 Annual Survey." Asia New Zealand Foundation.

- 2016. New Zealanders' Perceptions of Asia and Asian Peoples 2015 Annual Survey. Asia New Zealand Foundation.

Axelrod, Robert. 1984. Evolution of Cooperation. New York: Basic Books.

Ayson, Robert. 2013. "Choosing Ahead of Time?: Australia, New Zealand and the US-China Contest in Asia." Contemporary Southeast Asia: A Journal of International and Strategic Affairs 34 (3): 338-64.

Baker, Peter. 2017. “Trump Abandons Trans-Pacific Partnership, Obama's Signature Trade Deal." The New York Times, January 23, 2017, sec. Politics.

https://www.nytimes.com/2017/01/23/us/politics/tpp-trump-trade-nafta.html.

Barker, Fiona, David Capie, Fiona Barker, and David Capie. 2010. "Identity as a Variable in Canadian and New Zealand Politics." Political Science 62 (1): 3-10.

Barnett, Michael. 2002. Eyewitness to a Genocide: The United Nations and Rwanda. Cornell University Press.

Belich, James. 1997. "Myth, Race, and Identity in New Zealand.” New Zealand Journal of History 31 (1): 9-22.

Bowman, Scott, and Patrick Conway. 2013. "China's Recent Growth and Its Impact on the New Zealand Economy, New Zealand Treasury Working Paper 13/15.” New Zealand Treasury.

Boyd, Alex. 2016. "Anti-Nuclear New Zealand: A Report on the Decline of Anti-Nuclear Sentiment within the New Zealand Public National Identity." The Peace Foundation, New Zealand. http://www.nuclearfreenz30.org.nz/wp-content/uploads/2017/06/AlexBoyd-Nuclear-Report-PF.pdf.

Brown, David. 2004. "Why Independence? The Instrumental and Ideological Dimensions of Nationalism.” International Journal of Comparative Sociology 45 (3-4): 277-96. 
Brunk, Darren. 2008. "Dissecting Darfur: Anatomy of a Genocide Debate.” International Relations 22 (1): 25-44.

Buchanan, Paul. 2012. "Deconstructing New Zealand Foreign Policy.” Strategic Intelligence and Assessment. 36th Parallel (blog). August 1, 2012. http://36thparallel.com/2012/08/01/deconstructing-new-zealand-foreign-policy/.

Burchill, Scott. 2005. "Progressive Perspectives: Constructivism." In The National Interest in International Relations Theory, 185-205. Palgrave Macmillan UK. http://link.springer.com/chapter/10.1057/9780230005778_7.

Capie, David, and Gerald McGhie. 2005. "Representing New Zealand: Identity, Diplomacy and the Making of Foreign Policy." In New Zealand Identities: Departures and Destinations. Wellington: Victoria University Press.

Checkel, Jeffrey T. 1998. "The Constructive Turn in International Relations Theory." World Politics 50 (02): 324-48.

Clark, Helen. 2007. “Address at Oxford Union: 'New Zealand Foreign Policy', Oxford Union Debating Chamber Frewin Court, Oxford, England." http://www.scoop.co.nz/stories/PA0710/S00026.htm.

Clinton, Hillary. 2011. “America’s Pacific Century.” Foreign Policy (blog). 2011. https://foreignpolicy.com/2011/10/11/americas-pacific-century/.

Colmar Brunton. 2013. "Benchmark Survey of the New Zealand Public's Knowledge and Understanding of the First World War and Its Attitudes to Centenary Commemorations." First World War Centenary Programme Office.

Conley Tyler, Melissa, and Eleanor Pahlow. 2014. "Australia on the UN Security Council 2013-14: A Voice for Small and Medium Countries?" The Round Table 103 (1): 95108.

Cudworth, Anthon J. 2002. "Crisis and Decision: New Zealand and the Persian Gulf War, 1990/1991.” https://ir.canterbury.ac.nz/handle/10092/6666.

Daws, Sam, and Loraine Sievers. 2017. "Security Council Report: Arria-Formula Meetings, 1992-2017." United Nations Security Council.

http://www.securitycouncilreport.org/un-security-council-workingmethods/atf/cf/\%7B65BFCF9B-6D27-4E9C-8CD3-

CF6E4FF96FF9\%7D/working_methods_arria_formula.pdf.

Devetak, Richard, and Jacqui True. 2006. "Diplomatic Divergence in the Antipodes: Globalisation, Foreign Policy and State Identity in Australia and New Zealand." Australian Journal of Political Science 41 (2): 241-56.

Gordon, Michael R., and David E. Sanger. 2015. "Deal Reached on Iran Nuclear Program; Limits on Fuel Would Lessen With Time." The New York Times, July 14, 2015, sec. Middle East. https://www.nytimes.com/2015/07/15/world/middleeast/iran-nucleardeal-is-reached-after-long-negotiations.html.

Guibernau, Maria Montserrat. 2007. The Identity of Nations. Polity. 
Hawkins, George. 2003. "Speech on 30th Anniversary of NZ Government Sending Protest Frigates to Moruroa Atoll." The Beehive. July 28, 2003.

http://www.beehive.govt.nz/speech/speech-30th-anniversary-nz-government-sendingprotest-frigates-moruroa-atoll.

Headley, James, and Andreas Reitzig. 2012. "Does Foreign Policy Represent the Views of the Public? Assessing Public and Elite Opinion on New Zealand's Foreign Policy." Australian Journal of International Affairs 66 (1): 70-89.

Hobson, William, James Busby, and James Stuart Freeman. 1840. “The Treaty of Waitangi.”

Human Rights Watch. 2017. "Syria, Events of 2016.” Human Rights Watch. January 12, 2017. https://www.hrw.org/world-report/2017/country-chapters/syria.

_. n.d. "Human Rights Watch Report 1994: 8. Africa, Somalia.” Human Rights Watch. Accessed July 27, 2017. https://www.hrw.org/reports/1994/WR94/Africa-08.htm.

International Organization for Migration. 2015. "How the World Views Migration: Results from a New IOM/Gallup Report.” International Organization for Migration. October 16, 2015. https://www.iom.int/news/how-world-views-migration-results-newiomgallup-report.

Jeffries, James. 2015. "When Multilateralism Met Realism — and Tried to Make an Iran Deal | Foreign Policy.” Foreign Policy. August 11, 2015. http://foreignpolicy.com/2015/08/11/when-multilateralism-met-realism-iran-dealobama-administration-congress/.

Key, John. 2010a. "New Zealand in the World." New Zealand International Review 35(6) (2).

—. 2010b. "Statement to Parliament, New Zealand House of Representatives."

- 2016. "Prime Minister John Key's Full Speech at UN Security Council Meeting on Syria.” Stuff. September 22, 2016.

http://www.stuff.co.nz/national/politics/84530830/prime-minister-john-keys-fullspeech-at-un-security-council-meeting-on-syria.

King, Michael. 2003. Penguin History Of New Zealand. Penguin UK.

Ludlam, Scott. 2016. "Foreign Policy That Blindly Follows the US Isn't in Our National Interest." Sydney Morning Herald, January 18, 2016.

http://www.smh.com.au/comment/foreign-policy-that-blindly-follows-the-us-isnt-inour-national-interest-20160118-gm85xd.html.

McCraw, David J. 2000. "New Zealand's Foreign Policy in the 1990s: In the National Tradition?" The Pacific Review 13 (4): 577-94.

McKinnon, Malcolm. 2013. Independence and Foreign Policy: New Zealand in the World Since 1935. Auckland University Press.

McLay, Jim. 2011. "Making a Difference: The Role of a Small State at the United Nations." Juanita Voices 11: 121-34. 
Meisler, Stanley. 1993. "U.N. Refuses to Lift Bosnia Arms Embargo.” Los Angeles Times, June 30, 1993. http://articles.latimes.com/1993-06-30/news/mn-8607_1_bosnia-armsembargo.

Ministry of Foreign Affairs and Trade. 2010. "Wellington Declaration on a New Strategic Partnership between New Zealand and the United States of America, 04 November 2010." http://www.mfat.govt.nz/Media-and-publications/Features/665-Wellingtondeclaration-on-new-NZ-US-partnership.php.

New Zealand Government. 2012. "US-NZ Defence Arrangement Signed, 20 June 2012.” http://www.beehive.govt.nz/release/us-nz-defence-arrangement-signed.

- 2013. New Zealand: Candidate for the United Nations Security Council 2015-2016. Wellington.

New Zealand Government, and United States of America. 2012. "Washington Declaration on Defense Cooperation Between the Department of Defense of the United States of America and the New Zealand Ministry of Defence and the New Zealand Defence Force."

New Zealand Herald. 2014. "NZ Wins Seat on Security Council: 'Victory for the Small States." New Zealand Herald, October 17, 2014.

http://www.nzherald.co.nz/nz/news/article.cfm?c_id=1\&objectid=11343853.

- 2015. "NZ Credited for Focusing on Small Island States at UN Debate." New Zealand Herald, July 30, 2015.

http://www.nzherald.co.nz/nz/news/article.cfm?c_id=1\&objectid=11489855.

__. 2016a. "Kiwis Torn on US Ship Visits." New Zealand Herald, January 20, 2016. http://www.nzherald.co.nz/nz/news/article.cfm?c_id=1\&objectid=11576323.

_ 2016b. "Foreign Minister Murray McCully Was Warned of 'Declaration of War' by Israel PM - Report." New Zealand Herald, December 28, 2016, sec. New Zealand. http://www.nzherald.co.nz/nz/news/article.cfm?c_id=1\&objectid=11773841.

2017. "NZ Has Avoided United Nations Peacekeeping Missions because of Safety Concerns: McCully." New Zealand Herald, April 5, 2017.

New Zealand History. n.d. "History of the Māori Language - Māori Language Week." New Zealand History Online. Accessed July 20, 2017.

https://nzhistory.govt.nz/culture/maori-language-week/history-of-the-maori-language.

New Zealand Ministry for Culture and Heritage. 2008. "How Important Is Culture? New Zealanders' View in 2008 - An Overview."

New Zealand Ministry of Foreign Affairs and Trade. 1995. New Zealand in the Security Council, 1993-94. Information Bulletin 52. Wellington: New Zealand Ministry of Foreign Affairs and Trade. 
. 2010. "Wellington Declaration on a New Strategic Partnership between New

Zealand and the United States of America, 04 November 2010."

http://www.mfat.govt.nz/Media-and-publications/Features/665-Wellington-

declaration-on-new-NZ-US-partnership.php.

. 2013. New Zealand-China Free Trade Agreement.

n.d. "New Zealand and the UN Security Council 2015-16." New Zealand Ministry of

Foreign Affairs and Trade. Accessed August 3, 2017a.

https://www.mfat.govt.nz/en/peace-rights-and-security/work-with-the-un-and-other-

partners/new-zealand-and-the-un-security-council-2015-16/.

. n.d. "United Kingdom.” New Zealand Ministry of Foreign Affairs and Trade.

Accessed July 18, 2017b. https://www.mfat.govt.nz/en/countries-and-

regions/europe/united-kingdom/.

New Zealand Parliamentary Library. 2003. "Iraq and Disarmament, Parliamentary Briefing Note 2003/1.” New Zealand Parliament.

—. 2006. "Treaty of Waitangi Settlements Process, Research Paper 2006/04."

Nichols, Michelle. 2016. "New Zealand Pushes to Break U.N. Security Council Deadlock on Syria." Reuters, October 12, 2016. http://www.reuters.com/article/us-mideast-crisissyria-un-idUSKCN12C2QH.

Nye, Joseph S. 1988. "Neorealism and Neoliberalism.” World Politics 40 (02): 235-51.

2009. "Scholars on the Sidelines." The Washington Post, April 13, 2009.

http://www.washingtonpost.com/wp-

dyn/content/article/2009/04/12/AR2009041202260.html.

O’Brien, Terrence. 2013. “The Legacies of Super Power." New Zealand International Review 38 (No.2, March).

- 2015. "Getting around the Security Council Table." New Zealand International Review 40 (No. 1, January/February).

O'Brien, Terrence, Alistair McIntosh (ed.), and Malcolm McKinnon (ed.). 2007. "New Zealand in the International System." In New Zealand in World Affairs, 1990 - 2005. Wellington: Victoria University Press.

Osborne, Danny, Jennifer Lees-Marshment, and Clifton van der Linden. 2016. "National Identity and the Flag Change Referendum: Examining the Latent Profiles Underlying New Zealanders' Flag Change Support." New Zealand Sociology 31 (7): 19-47.

Oye, Kenneth A. 1985. "Explaining Cooperation Under Anarchy: Hypotheses and Strategies." World Politics 38 (01): 1-24.

Patman, Robert. 2005. "Globalisation, Sovereignty and the Transformation of New Zealand Foreign Policy." Centre for Strategic Studies, Victoria University of Wellington. 
Petri, Peter A., and Michael G. Plummer. 2012. "The Trans-Pacific Partnership and AsiaPacific Integration: Policy Implications." Peterson Institute for International Economics Policy Brief, Forthcoming. https://papers.ssrn.com/sol3/papers.cfm?abstract_id=2108399.

Phillips, Jock. 1991. "New Zealand and the Anzus Alliance: Changing National SelfPerceptions, 1945-88." In Australia, New Zealand and the United States: Internal Change and Alliance Relations in the ANZUS States, 183-202. New York: Praeger.

Pillar, Paul R. n.d. “American Interests, Russian Interests.” Text. The National Interest. Accessed August 3, 2017. http://nationalinterest.org/feature/american-interestsrussian-interests-18622.

Putnam, Robert D. 1988. "Diplomacy and Domestic Politics: The Logic of Two-Level Games.” International Organization 42 (3): 427-60.

Radio New Zealand. 2015. "New Zealand's 15-Year Role in Iraq." Radio New Zealand. October 7, 2015. http://www.radionz.co.nz/news/political/286365/new-zealand\%27s15-year-role-in-iraq.

Research New Zealand. 2014. "A Report on a Survey of New Zealanders about Their National Identity.” Research New Zealand.

Reuters. 2017. "Russia and China Veto UN Resolution to Impose Sanctions on Syria." The Guardian, March 1, 2017, sec. World news.

http://www.theguardian.com/world/2017/mar/01/russia-and-china-veto-un-resolutionto-impose-sanctions-on-syria.

Risse, Thomas, Daniel Engelmann-Martin, Hans-Joachim Knope, and Klaus Roscher. 1999. "To Euro or Not to Euro?: The EMU and Identity Politics in the European Union." European Journal of International Relations 5 (2): 147-87.

Sciboz, Joëlle. n.d. "Research Guides: Security Council - Quick Links: Vetoes.” Research starter. Accessed July 25, 2017. http://research.un.org/en/docs/sc/quick/veto.

Sibley, Chris, William James Hoverd, and James H. Liu. 2011. "Pluralistic and Monocultural Facets of New Zealand National Character and Identity." New Zealand Journal of Psychology 40 (No. 3): 19-29.

Sil, Rudra, and Peter J. Katzenstein. 2010a. "Analytic Eclecticism in the Study of World Politics: Reconfiguring Problems and Mechanisms across Research Traditions." Perspectives on Politics 8 (2): 411-31.

- 2010b. Beyond Paradigms: Analytic Eclecticism in the Study of World Politics. Palgrave Macmillan.

Skilling, Peter. 2010. "The Construction and Use of National Identity in Contemporary New Zealand Political Discourse.” Australian Journal of Political Science 45 (2): 175-89.

Small, Vernon. 2015. “Labour Backs S. Korea Deal.” Stuff. March 27, 2015. http://www.stuff.co.nz/national/politics/67531523/labour-supports-south-korea-freetrade-deal. 
. 2016. "No 'Confirm or Deny' Required from US for Ship Visit, Says McCully." Stuff, June 12, 2016. http://www.stuff.co.nz/national/politics/80975944/no-confirmor-deny-required-from-us-for-ship-visit-says-mccully.

Smith, Adam C. 2014. "Peacekeeping Contributor Profile: United States of America." Providing for Peacekeeping. March 2014.

http://www.providingforpeacekeeping.org/2014/04/03/contributor-profile-unitedstates-of-america/.

Statistics New Zealand. 2002. "2001 Census Snapshot 1: Cultural Diversity.” Statistics New Zealand.

- 2011. Social Cohesion in New Zealand: Facts from the New Zealand General Social Survey 2008. Wellington: Statistics New Zealand.

- 2015a. China-New Zealand Trade, Investment, and Migration: Year Ended December 2014.

_ 2015b. "United States-New Zealand Trade, Investment, and Migration: Year Ended December 2014."

—. 2017. "Information Release: Well-Being Statistics: 2016." Statistics New Zealand.

_ n.d. "2013 Census QuickStats about Culture and Identity.” Accessed July 18, 2017. http://www.stats.govt.nz/Census/2013-census/profile-and-summaryreports/quickstats-culture-identity.aspx.

Taonga, New Zealand Ministry for Culture and Heritage Te Manatu. n.d. "3. - Britain, Europe and New Zealand - Te Ara Encyclopaedia of New Zealand." Web page. Accessed July 18, 2017a. /en/britain-europe-and-new-zealand/page-3.

- n.d. "Political Values - Te Ara Encyclopedia of New Zealand." Web page. Accessed July 22, 2017b. /en/political-values.

Templeton (ed.), Malcolm. 1995. New Zealand as an International Citizen: Fifty Years of United Nations Membership. Ministry of Foreign Affairs and Trade.

Thorhallsson, Baldur. 2012. "Small States in the UN Security Council: Means of Influence?" The Hague Journal of Diplomacy 7 (2): 135-60.

TVNZ. 2017. “Opinion: NZ's 'Independent' Foreign Policy Is a Myth,” July 7, 2017, sec. New Zealand. https://www.tvnz.co.nz/one-news/new-zealand/opinion-nzsindependent-foreign-policy-myth.

United Nations. 1945. Charter of the United Nations. http://www.un.org/en/charter-unitednations/.

. 2015. "Issues Facing Small Island Developing States 'Global Challenges' Demanding Collective Responsibility, Secretary-General Tells Security Council, Press Release SC/11991." United Nations | Meetings Coverage and Press Releases. July 30, 2015. https://www.un.org/press/en/2015/sc11991.doc.htm. 
n.d. "Chapter XVIII, Penal Matters: 8. Convention on the Safety of United Nations and Associated Personnel." United Nations Treaty Collections. Accessed July 27, 2017a.

https://treaties.un.org/pages/ViewDetails.aspx?src=TREATY\&mtdsg_no=XVIII$8 \&$ chapter $=18 \&$ clang $=$ en.

n.d. "Security Council Subsidiary Bodies: An Overview." Www.un.org. Accessed July 25, 2017b. https://www.un.org/sc/suborg/en/.

United Nations Office for Disarmament Affairs. n.d. "Comprehensive Nuclear-Test-Ban Treaty (CTBT)." Accessed July 22, 2017.

https://www.un.org/disarmament/wmd/nuclear/ctbt/.

United Nations Security Council. 1993. "United Nations Security Council Resolution 868, S/RES/868 (1993)." http://www.un.org/en/ga/search/view_doc.asp?symbol=S/RES/868(1993).

—. 1994. "Statement by the President of the Security Council, S/PRST/1994/62." http://www.un.org/en/ga/search/view_doc.asp?symbol=S/PRST/1994/62.

_. 2015. "Security Council, Adopting Resolution 2231 (2015), Endorses Joint Comprehensive Agreement on Iran's Nuclear Programme." United Nations | Meetings Coverage and Press Releases. July 20, 2015.

https://www.un.org/press/en/2015/sc11974.doc.htm.

— 2016a. "Draft United Nations Security Council Resolution on Syria, S/2016/846." http://www.un.org/en/ga/search/view_doc.asp?symbol=S/2016/846.

— . 2016b. "Egypt, New Zealand and Spain: Draft Resolution on Syria S/2016/1026." http://www.un.org/en/ga/search/view_doc.asp?symbol=S/2016/1026.

- n.d. "Background Note on the 'Arria-Formula' Meetings of the Security Council Members." United Nations Security Council. Accessed August 1, 2017. http://www.un.org/en/sc/about/methods/bgarriaformula.shtml.

Varshney, Ashtoush. 2007. "Ethnicity and Ethnic Conflict." In The Oxford Handbook of Comparative Politics, edited by C Boix and S Stokes. Oxford: Oxford Univiersity Press.

Walt, Stephen. 1984. The Origin of Alliances. London: Cornell University Press.

Waltz, Kenneth. 1979. Theory of International Politics. New York: McGraw Hill.

Watkins. 2014a. "NZ Welcomed back to Spy Network." Stuff, June 20, 2014. https://www.stuff.co.nz/national/10184624/NZ-welcomed-back-to-spy-network.

Watkins, Tracey. 2014b. “'We Nailed It': NZ Wins UN Security Council Seat.” Stuff, October 17, 2014. http://www.stuff.co.nz/world/europe/62487701/we-nailed-it-nzwins-un-security-council-seat. 
. 2016a. "Key Blasts UN Security Council over 'Vested Interests' Preventing Action on Syria." Stuff. September 21, 2016.

http://www.stuff.co.nz/national/politics/84500371/key-blasts-un-security-councilover-vested-interests-preventing-action-on-syria.

. 2016b. "No Regrets - John Key Reflects on New Zealand's UN Security Council Term." Stuff. September 23, 2016.

http://www.stuff.co.nz/national/politics/84576831/no-regrets--john-key-reflects-onnew-zealands-un-security-council-term.

Watts, William. 1991. "Australia, New Zealand and the United States: Mutual Perceptions." In Australia, New Zealand and the United States: Internal Change and Alliance Relations in the ANZUS States. New York: Praeger.

Wendt, Alexander. 1992. "Anarchy Is What States Make of It: The Social Construction of Power Politics.” International Organization 46 (02): 391-425.

What's In Blue. 2016. “Arria-Formula Meeting with Human Rights Components in Peace Operations." What's In Blue. March 1, 2016.

http://www.whatsinblue.org/2016/03/arria-formula-meeting-with-human-rightscomponents-in-peace-operations.php.

Wiharta, Sharon. 2010. "Jan. 11: The Politics of Peacekeeping in Africa: The End of Indifference?" Stockolm International Peace Research Institute. December 15, 2010. https://www.sipri.org/commentary/essay/wed-12-15-2010-13-00/jan-11-politics-ofpeacekeeping-africa-end-of-indifference.

Witte, Griff. 2015. "New U.N. Report Says World's Refugee Crisis Is Worse than Anyone Expected." The Washington Post, June 18, 2015.

https://www.washingtonpost.com/world/europe/new-un-report-says-worlds-refugeecrisis-is-worse-than-anyone-expected/2015/06/17/a49c3fc0-14ff-11e5-84574b431bf7ed4c_story.html?utm_term $=.2 \mathrm{ec} 1 \mathrm{~b} 3875621$.

Young, Audrey. 2016a. "United States Ship to Visit NZ for First Time in 33 Years.” New Zealand Herald, July 21, 2016.

http://www.nzherald.co.nz/nz/news/article.cfm?c_id=1\&objectid=11678267.

2016b. "NZ Talks to Kerry about UN Security Council Resolution on IsraelPalestine Conflict." NZ Herald, November 13, 2016, sec. New Zealand. http://www.nzherald.co.nz/nz/news/article.cfm?c_id=1\&objectid=11747382.

2017. "Diplomat Says UN Security Council Experience Has Enhanced New Zealand's Reputation." NZ Herald, March 15, 2017, sec. New Zealand. http://www.nzherald.co.nz/nz/news/article.cfm?c_id=1\&objectid=11819420.

Young, Jason. 2017. "Seeking Ontological Security through the Rise of China: New Zealand as a Small Trading Nation." The Pacific Review 30 (4): 513-30. 